\title{
The Welfare Consequences of Mergers with Endogenous Product Choice*
}

\author{
Michael J. Mazzeo ${ }^{\dagger} \quad$ Katja Seim ${ }^{\ddagger} \quad$ Mauricio Varela ${ }^{\S}$
}

August 25, 2018

\begin{abstract}
Merger simulations focus on the price changes that may occur once previously independent competitors set prices jointly and other market participants respond. This paper considers the possibility that market participants adjust the set of products they offer after a merger. Using a model that endogenizes both product choice and pricing, we conduct simulations of equilibrium market outcomes of a merger in a variety of scenarios. We find that allowing for changes in product offering can have effects on profitability and consumer welfare above and beyond those generated by traditional price responses alone, particularly in cases where the merging parties offer relatively similar products prior to the merger. Cost synergies may also affect product offering decisions, potentially leading to increases in consumer welfare if more products are introduced. The results suggest that analysts carefully consider the impacts of product choice, along with prices, when assessing potential welfare changes of mergers.
\end{abstract}

Keywords: product positioning decisions, market structure, merger analysis JEL Classification: L10, L40, L80

${ }^{*}$ We thank Steve Berry, Michaela Draganska, Ying Fan, Paul Grieco, Evan Glover, Mark Israel, two anonymous referees, the editor, and seminar and conference participants at Northwestern Law School Searle Center Conference on Antitrust Economics and Competition Policy, Bates White, Industrial Organization Society Conference, ASSA Annual Meeting, Haas School of Business (UC-Berkeley), Purdue University and CEPR/JIE Industrial Organization Conference, and the Annual FTC Microeconomics Conference for comments and suggestions.

${ }^{\dagger}$ Kellogg School of Management, Northwestern University, Evanston, IL 60208. E-mail: mazzeo@kellogg.northwestern.edu

${ }^{\dagger}$ Business Economics and Public Policy Department, University of Pennsylvania, Philadelphia, PA 19104. E-mail: kseim@wharton.upenn.edu

${ }^{\S}$ Corresponding author. Department of Economics, University of Arizona, Tucson, AZ 85721. E-mail: mvarela@email.arizona.edu 


\section{Introduction}

Over the past decades, advances in industrial organization economics, in particular in the estimation of equilibrium models of demand and pricing, have had an increasing impact on the analysis of horizontal mergers. Using data from the industry of the proposed merger, an analyst can assess the relationship between market concentration and price changes and predict how prices would adjust following the merger of two industry participants. This approach - empirical demand elasticity and marginal cost estimation followed by merger simulation of the proposed ownership change given the estimated preferences and costs has been used as suggestive evidence of the likely effects of a merger on prices charged to consumers. $^{1}$

This paper addresses one shortcoming of this approach. While it explicitly includes prices as choice variables of the industry participants, it treats firms' product offerings -as fixed effectively imposing the assumption that industry participants cannot choose to adjust product offerings after the merger. This abstraction has consequences for the accuracy of merger simulations. $^{2}$ We use a series of simulation exercises to conduct a detailed examination of the implications of allowing for both price and product portfolio changes after a merger based on two settings - a stylized case with identically, horizontally differentiated products and a more realistic example motivated by an empirical case. In our settings, competing firms have created a menu of differentiated product offerings from which they choose a subset to offer in a given period. For simplicity, we consider three single-product firms, each of whom are endowed with one product; the three products are horizontally equidistant.

Permitting firms to reconsider product offering decisions after a merger generates more complex incentives for firm behavior and corresponding effects on consumer surplus. In some cases, for example, the merged firm may choose not to offer products that are close substitutes in product space. Alternatively, industry participants (both the merged firm and others) may choose to expand their product offerings given a new ownership structure. Impacts on consumer welfare associated with price increases may be reduced if consumers value characteristics of products that are increasingly made available after a merger. Our simulations allow us to tease apart these potentially offsetting effects and the contributions of product portfolio adjustments to the overall assessment. Such considerations may be important in merger evaluation, especially when parties argue that entry behavior by other

$1 \quad$ Budzinski and Ruhmer (2010) provide a recent survey of merger simulation in competition policy.

2 It is worth noting that authors who have proposed the use of differentiated product demand models for merger simulation are well aware of the abstraction from post-merger product selection inherent in their approach. For example, Nevo (2000) states, "this approach is not consistent with firms changing their strategies in other (than price) dimensions that may influence demand... this implies that characteristics, observed and unobserved,... are assumed to stay the same pre- and post-merger." 
market participants (e.g., US vs. Oracle) or product introduction decisions by more efficient competitors (e.g., FTC vs. H.J. Heinz Co.) can mitigate the effects of market power. ${ }^{3}$

Our approach builds on existing theoretical and empirical work that explores the effects of endogenous entry and product choice decisions on merger evaluations. For example, the findings in Berger et al. (2004) suggest that de novo entry follows mergers in the banking industry. Analyses by Werden and Froeb (1998), Cabral (2003), and Spector (2003) explore whether the presence of sunk entry costs may dissuade a potential entrant (that would counter market power effects were it to enter) from joining the industry after a merger. Gowrisankaran (1999) and Marino and Zabojnik (2006) expand to a dynamic analysis that examines the effects of mergers on entry and exit over time. These papers focus on the subsequent effect on price that entry may or may not mitigate. More recent work by Jeziorski (2014)studies the effects of cost efficiencies on mergers and repositioning in a dynamic setting.

On the theory side, our paper is closest to Gandhi et al. (2008). Like ours, their paper analyses the behavior of a fixed number of market participants that can change their product choices after a merger. Specifically, they propose a Hotelling (1929) set-up, in which single outlet firms (stores) can optimally change their product space location, along with price, after a merger. For a wide range of utility and cost parameterizations, merging parties that previously offered similar products move further away from each other in product space, as it is more profitable to avoid cannibalization. The remaining industry participants also alter their product space locations. The authors conclude that "the merged firm's product repositioning both mitigates the reduction in consumer welfare the merger otherwise would produce and allows the merged firm to capture a much larger portion of the profits the merger generates." Note that this 'repositioning' approach contrasts with our model, where the industry participants have pre-set products at various product space locations and endogenously choose to offer (or not) them pre- and post-merger.

Either approach to endogenizing product selection may be appropriate, depending on the conditions in the industry in question, as recent empirical work on endogenous product choice in merger analysis demonstrates. Fan (2013)'s study of the newspaper industry includes a fully developed equilibrium model of demand, firms' joint pricing (here, subscription and advertising rates) and product characteristic choices, such as news quality, measured as continuous indices. She uses the estimated demand, marginal cost of circulation and advertising acquisition, and marginal cost of improving news quality to simulate the adjustment in news quality and prices in response to consolidation between two competing newspapers. Notably, simulations of both a proposed and ultimately blocked merger and in hypothetical mergers

3 Section 6.1 of the 2010 revision of the Horizontal Merger Guidelines indicates that the DOJ and FTC consider product offering decisions when evaluating potential merger effects. 
between local competitors, firms reduce news quality, generating consumer surplus losses beyond those due to higher prices alone. The set-up in Wollmann (2016) is more similar to ours - market participants in the truck manufacturing industry can choose from a menu of discrete options that vary in a smaller number of horizontal characteristics (e.g., size, cab design). Data on the products offered by various market participants allows inferences of the sunk costs of offering a particular product from each firm's menu. Wollmann (2016) then uses these sunk cost estimates to simulate new market structure patterns after a change due, for example, to a merger. ${ }^{4}$

We begin by outlining our modeling approach, which generalizes the work of Draganska et al. (2009). Firms play a two-stage game: optimally choosing whether to offer products from their available menu in the first stage and then competing on price with those choices in the second stage. To highlight the primary trade-offs at hand, we begin with a classic base case where firms compete with products that, although differentiated for individual consumers, have equal demand when aggregating across consumers. A downside to this base case is that as products are identical in terms of aggregate consumer welfare, the identity of the products that firms choose to offer pre- and post-merger does not affect overall consumer welfare. We therefore also consider an extension where we allow products to be vertically differentiated. To ground the second set of merger simulations in a reasonable empirical setting, we estimate a differentiated products demand system using data from the ice cream market to generate parameter estimates for preferences and marginal costs.

We then rely on the base set of preferences and the stylized ice cream setting to carry out a series of merger simulations, allowing for both price and product offering changes postmerger. For both sets of preferences, we consider how the merger assessment changes as we vary two key primitives of our model across a range of empirical relevance, including, in the second case, the values we estimate. These primitives are the distance of products in productcharacteristics space, which drives substitution between products relative to substitution to the outside option, and the fixed cost of offering products, which offsets variable profit in determining the overall profitability of offering each product. Finally, we highlight alternative motivations underlying a merger and tease out their effects on welfare after the merger.

The results from our simulations confirm that once we allow for product portfolio adjustments, the number of products offered, the differentiation between offered products, and consumer welfare post-merger may be substantially different from "price only" merger simulations. In analyzing various incentives for firms to change offerings post-merger, our

$4 \quad$ Other applications include Li et al. (2018), which also considers discrete repositioning in the context of non-stop or connecting airline service, and the work by Fan and Yang (2018) on product offering changes following mergers in the market for smartphones. 
simulations demonstrate offsetting effects: higher prices post-merger induce firms - either the merging parties or their rivals - to offer more varieties, but the merged firm can save on costs by not offering duplicate products with similar characteristics. Both with symmetric products and with vertically differentiated products, we find that for most preference parameters we study, the latter incentive dominates: the merged firms reduce the number of products offered. This reduction induces a further substantial consumer welfare loss, as consumers' options are diminished and prices increase due to the decrease in available products as well as the channel of joint pricing by the merged firm. This result contrasts with the findings in Gandhi et al. (2008) who find that when endogenizing product locations (but holding the number of offered products fixed) estimates of welfare losses induced by a horizontal merger are not as large as would be predicted by merger simulations that allow only price, but not product locations, to adjust post merger.

In summary, we make two contributions. First, we illustrate the response in firms' strategic choices (their product portfolios and prices) and market outcomes (profit and consumer welfare) to a merger as we vary the degree of horizontal differentiation between products. To highlight different mechanisms behind product offering adjustments post-merger, we employ a series of simulation exercises that condition on a wider range of possible pre-merger market structures than a single empirical setting would easily allow. Second, the range of preferences we consider highlights the inherent flexibility of our analysis. Our approach to calibrating the primitives of the model from commonly derived outputs of an empirical demand estimation furthermore serves as an example of how one might assess the product variety implications of a merger in an initial step before engaging in a fully developed empirical analysis. Determining these responses is straightforward once demand estimates have been determined and the available product portfolios are known; therefore, putting these effects together as we do can be useful in applied policy settings.

We proceed as follows. Section 2 outlines a two-stage game of product portfolio choice and pricing between differentiated products firms, highlighting model primitives - consumers' heterogeneous preferences for these products, their price sensitivity, and firms' marginal cost of producing each product and their fixed cost of offering them - that drive the subsequent merger assessments we perform. In Section 3, we use the product offering model to assess the aggregate effects of various hypothetical mergers in a simple symmetric industry, before turning to the stylized version of the ice cream industry. Section 4 considers the role of merger-induced variable or fixed cost savings in mitigating the consumer welfare consequences of price and product portfolio adjustments post-merger. Section 5 concludes. 


\section{A Model of Endogenous Product Choice}

We begin by outlining a model of competition among firms offering differentiated products, within which we can analyze the product offering decision in the context of merger simulation. While the model is restricted to three firms for simplicity of exposition - two of whom merge, while the third represents the experience of non-merging parties - it can be readily expanded to include any number of firms.

Consider an industry with three firms identified by $i \in\{A, B, C\} \equiv I$. Each firm has an established portfolio of products with predefined characteristics. $\mathcal{J}_{i}$ represents the set of products for firm $i$ and $j$ represents one of these products. The game has two stages: in the first stage, firms simultaneously choose which products to offer from their portfolio and incur an entry fee for each product, which ought to be thought of as the fixed cost of offering each product. In the second stage, after observing all competitors' chosen product sets, firms choose prices simultaneously for each of their offered products.

We only consider pure strategy, sub-game perferct, Nash equilibria. Let the equilibria from this two stage game be denoted $\left(\mathbf{x}^{\star}, \mathbf{p}^{\star}\right)$. In particular, $\mathbf{x}^{\star}$ represents the entry decision for each firm: $\mathbf{x}^{\star} \equiv\left(\mathbf{x}_{A}^{\star}, \mathbf{x}_{B}^{\star}, \mathbf{x}_{C}^{\star}\right)$, where $\mathbf{x}_{A}=\left(x_{1 A}, x_{2 A}, \ldots, x_{j A}\right)^{\prime}$ and $x_{1 A}$ is an indicator that is one if the product is offered and zero if it is not. The price vector, $\mathbf{p}^{\star} \equiv\left(\mathbf{p}_{A}^{\star}, \mathbf{p}_{B}^{\star}, \mathbf{p}_{C}^{\star}\right)$, represents the equilibrium prices for all offered products $\mathbf{x}^{\star}$.

We characterize the equilibrium by solving the game through backward induction. For a given offering choice $\mathbf{x}$ we find the equilibrium prices of the simulteanous move subgame and calculate the subsequent profits and consumer surplus. Using these profits we then model a simulteanous move entry game and characterize its equilibrium. We provide detail on the profit functions and the entry game in the next subsections.

\subsection{The Pricing Game}

The offering choices are given by $\mathbf{x}$ and are taken as fixed in this subsection. Here we characterize the pricing game given the offering $\mathbf{x}$. Define $\mathcal{K}_{i}$ to be the set of firm $i$ 's active products, so that $\mathcal{K}_{i} \subseteq \mathcal{J}_{i}$ and $\mathcal{K}$ are all the products offered in the market: $\mathcal{K} \equiv \cup_{i \in I} \mathcal{K}_{i}$.

We model the pricing game assuming discrete choice consumer demand functions. A consumer $n$ has a particular preference for each product, yielding utility given by

$$
u_{j n}=\theta_{j n}-\alpha p_{j}+\epsilon_{j n}
$$

and that of not purchasing is given by $u_{0 n}=\epsilon_{0 n}$. Here, $\alpha$ is the consumer's price coefficient (his utility of income) and $\left(\theta_{j n}, \epsilon_{j n}\right)$ are two idiosyncratic taste shocks. $\theta_{j n}$ is drawn from 
an arbitrary distribution that allows for correlated shocks across products and non-zero means: $\theta_{n} \equiv\left(\theta_{1 n}, \theta_{2 n}, \ldots, \theta_{J n}\right)^{\prime} \sim F\left(\theta \mid \mu_{F}, \Sigma_{F}\right)$. In most applied work, $\theta_{j n}$ is a linear function of observed covariates and random taste shocks: $x_{j} \beta_{n}+\zeta_{j n}$ where $\left(\beta_{n}, \zeta_{j n}\right)$ are random variables distributed according to some parameterized distribution. We instead assume that $\theta_{j n}$ follows a multivariate normal distribution with mean $\mu_{F}$ and variance-covariance matrix that results in products being 'horizontally' equidistant, with equal correlation between $\theta_{j}$ and $\theta_{j^{\prime}}$ for each pair of products $j$ and $j^{\prime}, \rho$ :

$$
\Sigma_{F}=\left[\begin{array}{lll}
1 & \rho & \rho \\
& 1 & \rho \\
& & 1
\end{array}\right]
$$

$\rho$ captures the distance between products in preference space, with preferences for close products being highly correlated. We therefore also describe $\rho$ as the travel parameter in the below. $\epsilon_{j n}$ is drawn from a Type 1 Extreme Value (T1EV) distribution with scale parameter $\sigma$.

Let $M$ be the total number of consumers. The additivity and independence assumptions between the two idiosyncratic shocks $\left(\theta_{j n}, \epsilon_{j n}\right)$ allows us to integrate the probability of purchase in two steps, where the demand for product $j$ is given by

$$
s_{j}(\mathbf{p})=M \int \frac{e^{\frac{1}{\sigma}\left(\theta_{j n}-\alpha p_{j}\right)}}{1+\sum_{k \in \mathcal{K}} e^{\frac{1}{\sigma}\left(\theta_{k n}-\alpha p_{k}\right)}} d F\left(\theta_{n} \mid \mu_{F}, \Sigma_{F}\right)
$$

The scale parameter $\sigma$ controls the "smoothness" of the integrand in Equation 3 and defines how important price and the taste correlations across products are relative to other unobserved characteristics. One interpretation of the idiosyncratic shock $\epsilon$ is thus a convenience tool that is used to form a Kernel to approximate the outer integral over the random coefficients, $\theta_{j n}$, with $\sigma$ controlling the bandwidth of this Kernel.

Assuming a product-specific constant marginal cost $c_{j}$, firm $i$ 's profits in the pricing game are

$$
\pi^{i}(\mathbf{p})=\sum_{j \in \mathcal{K}_{i}} s_{j}(\mathbf{p})\left(p_{j}-c_{j}\right)
$$

and the equilibrium prices are defined as the solution to

$$
\frac{\partial \pi^{i}(\mathbf{p})}{\partial p_{j}}=0 \forall j \in \mathcal{K}_{i} i=\{A, B, C\}
$$

Vives (2001) shows that an equilibrium in the above game exists and is unique provided 
the game is supermodular, which results from profits being supermodular in own prices and exhibiting increasing differences in own prices and each rival firm's prices. Irrespective of the supermodularity of the game, Caplin and Nalebuff (1991) furthermore establish the existence of equilibria for the case of single-product firms. Lastly, Aksoy-Pierson et al. (2013) show that a sufficient condition for the equilibrium to exist and be unique is, even with multi-product firms and the absence of a supermodular game, is that mean utilities, $\mu_{F}$, be sufficiently low such that the market is not too concentrated..

Let $\mathbf{p}_{\mathbf{x}}$ define the equilibrium prices when the offering choice is $\mathbf{x}$ and let $\pi_{\mathbf{x}}$ denote the associated equilibrium variable profit. Before moving on to the entry game, we present the calculations for consumer surplus and price elasticities. Given the current setup, for an offering vector $\mathbf{x}$, consumer surplus can be defined as

$$
C S_{\mathbf{x}}=\int M \sigma \ln \left[1+\Sigma_{k \in \mathcal{K}} e^{\frac{1}{\sigma}\left(\theta_{k n}-\alpha p_{k, \mathbf{x}}\right)}\right] d F\left(\theta_{n} \mid \mu_{F}, \Sigma_{F}\right)
$$

which is a measurement of the equivalent variation as in McFadden (1973), modified to account for the random coefficients. Price elasticities are given as

$$
\eta_{j j^{\prime}}\left(\mathbf{p}_{\mathbf{x}}, \mathbf{x}\right)=\frac{p_{j^{\prime}}}{s_{j}\left(\mathbf{p}_{\mathbf{x}}\right)} \frac{d s_{j}\left(\mathbf{p}_{\mathbf{x}}\right)}{d p_{j^{\prime}}} \quad\left\{j, j^{\prime}\right\} \in \mathcal{K}
$$

\subsection{The Entry Game}

We model a simultaneous move entry game. For this game, we take the vector of profits $\pi_{\mathbf{x}}$ as the subgame outcomes of the entry game and assume no discounting. Firm $i$ incurs a cost $g_{j}$ of offering product $j$, which we group together in the vector $\mathbf{g}_{i} \equiv\left(g_{1}, g_{2}, \ldots, g_{J_{i}}\right)^{\prime}$, for $J_{i} \equiv\left|\mathcal{J}_{i}\right|$. In summary, the ex-post net profits for firm $i$ of offering products $\mathbf{x}_{i}$ are

$$
\Pi_{i}\left(\mathbf{x}_{i}, \mathbf{x}_{-i}\right)=\pi_{\left(\mathbf{x}_{i}, \mathbf{x}_{-i}\right)}-\mathbf{g}_{i}^{\prime} \cdot \mathbf{x}_{i}
$$

We assume complete information: all players know $\Pi_{i}\left(\mathbf{x}_{i}, \mathbf{x}_{-i}\right)$. Hence, a firm chooses an optimal offering given rival players' offerings and their own fixed costs:

$$
x_{i}^{\star}\left(\mathbf{g}_{i}, \hat{\mathbf{x}}_{-i}\right)=\arg \max _{\mathbf{x}_{i}} \Pi_{i}\left(\mathbf{x}_{i}, \hat{\mathbf{x}}_{-i}\right)
$$

In equilibrium, firm $i$ offers the set of products that, given its rivals' product offerings, maximizes its profit net of fixed product offering costs. The game may have multiple equilibria, and in the simulations that follow we analyze all possible equilibria. In these simulations we consider the driving forces behind the differential merger response, assess their significance, 
and compare them to the effects a price-only merger simulation would reveal.

\section{Simulations of Potential Merger Effects}

The model described above could apply to a wide range of preference parameterizations and cost distributions. To highlight the role of a merger on post-merger product offering choices, we consider the simplest such setting where each of the three firms offers one product each pre-merger. Post-merger, the newly merged entity thus has a two-product portfolio, and we analyze its incentives to continue selling both products, its full portfolio, or withdrawing one of them. We consider a parameterization of demand and variable costs that represents a case where products are horizontally equidistant and markups and price elasticities are consistent with commonly observed levels across industries. For robustness, we also consider a second setting that allows for variation in vertical and horizontal differentiation. In guiding our specification of preferences and costs in this second case, we rely on calibrated parameters using data from the premium ice cream market, an industry where product offering adjustments are common (see Draganska et al. (2009)).

\subsection{Aggregate Effects in a Hypothetical Symmetric Industry}

Table 1 shows the demand and cost parameters for the first setting of horizontally equidistant products. We normalize variable costs to one and choose mean utility parameters and the price coefficient such that equilibrium market shares and elasticities are 0.25 and -2.5 , respectively, when all three products are offered and when there is no correlation in random tastes (i.e. the travel parameter $\rho$ in Equation 2 is zero). We set the T1EV scale parameter of the distribution of $\epsilon_{j s}$ to 0.1 so that variation in horizontal differentiation, i.e. in the travel parameter $\rho$, may have a large impact on market outcomes. We normalize market size to one, but this normalization is without loss of generality as we explore market outcomes for various fixed cost values (i.e. $\mathbf{g}_{i}$ in Equation 8); only the ratio of fixed costs to market size affects market outcomes. We vary the products' fixed costs between 0 and an upper bound $\bar{\pi}$, where $\bar{\pi}$ is equal to the equilibrium variable profits generated by the given product when it does not compete against any other product. At this upper bound, firms choose not to offer any products. In the graphs below, we express a particular fixed cost value as a percentage of this upper bound.

Finally, we do not fix the travel parameter at a specific value, but show market outcomes as we vary it between zero and one, covering the full range of feasible positive values. ${ }^{5}$ The

$\overline{5}$ Although $\rho$ could span from -0.5 to 1 and $\Sigma_{F}$ would still retain positive definiteness, at $\rho=0$ products 
Table 1: Demand and Variable Cost Parameters - Symmetric Industry Setting

\begin{tabular}{rccccccc}
\hline \multicolumn{3}{c}{ (a) Product Specific Values } & & & \multicolumn{3}{c}{ (b) Common Values } \\
& $\mathrm{A}$ & $\mathrm{B}$ & $\mathrm{C}$ & & & \\
\cline { 1 - 4 } \cline { 7 - 8 } Mean Utility $\left(\mu_{F}\right)$ & 1.87 & 1.87 & 1.87 & & Price Coefficient $(\alpha)$ & -1.32 \\
Variable Cost $(c)$ & 1.0 & 1.0 & 1.0 & & T1EV Scale $(\sigma)$ & 0.1 \\
Fixed Cost $\left(g_{i}\right)$ & {$[0, \bar{\pi}]$} & {$[0, \bar{\pi}]$} & {$[0, \bar{\pi}]$} & & & & \\
Market Share $(\%)^{*}$ & $25 \%$ & $25 \%$ & $25 \%$ & & Market Size $(M)$ & 1.0 \\
Price* & 1.67 & 1.67 & 1.67 & & Travel Parameter $(\rho)$ & {$[0,1]$} \\
Elasticity* & -2.5 & -2.5 & -2.5 & & & \\
\hline
\end{tabular}

* Equilibrium outcome values when all three products are being offered and the travel parameter, $\rho$, is zero.

travel parameter captures the degree of differentiation between products, but its particular value is difficult to put in context. Instead, in the graphs that follow, we translate the particular choice of $\rho$ into a diversion ratio, which we report in place of the underlying value of $\rho$. The diversion ratio of product $A$ to product $B$ is defined as $-\frac{\partial s_{B}}{\partial p_{A}} / \frac{\partial s_{A}}{\partial p_{A}}$. We evaluate diversion ratios at equilibrium prices, conditional on all three products being offered. We divide the range of $\rho$ values from 0 to 1 into a 150-point grid, with grid points spaced at a decreasing distance such that the resulting grid of diversion ratios implied by each value of $\rho$ is equally spaced.

In a setting where three firms can offer one product each, there are eight possible market structures to consider. We start by considering market structure outcomes that arise when all three products are owned by separate firms, the pre-merger setting. Figure 1 shows these market structures for various values of the travel parameter, translated into diversion ratios from product $A$ to product $B$ shown on the x-axis, and various values of fixed costs, shown on the $\mathrm{y}$-axis as a percent of the highest break-even upper bound $\bar{\pi}$. Note that since the products are symmetric, diversion ratios between the other combinations of products are identical to the diversion ratio from $A$ to $B$. In order to plot all three products' fixed costs on a single axis, we vary them simultaneously, such that a value of 80 on the $y$-axis refers to a level of each product's fixed cost that is $80 \%$ of $\bar{\pi}$. We summarize market structures with the letters of the products that firms offer given the combination of fixed cost and travel parameter values. In the case of multiple equilibria, we show all possible equilibria, separating each equilibrium with a comma. Hence, the label " $A, B, C$ " denotes the case where three possible equilibria exist, each consisting of a single product being offered. In contrast, a market structure labeled " $A B C$ " captures the single unique equilibrium in which all three products are offered.

are already poor substitutes to each other. Lowering $\rho$ further hardly separates products further, resulting in no additional effects of interest. 
Figure 1: Pre-merger equilibrium market structures

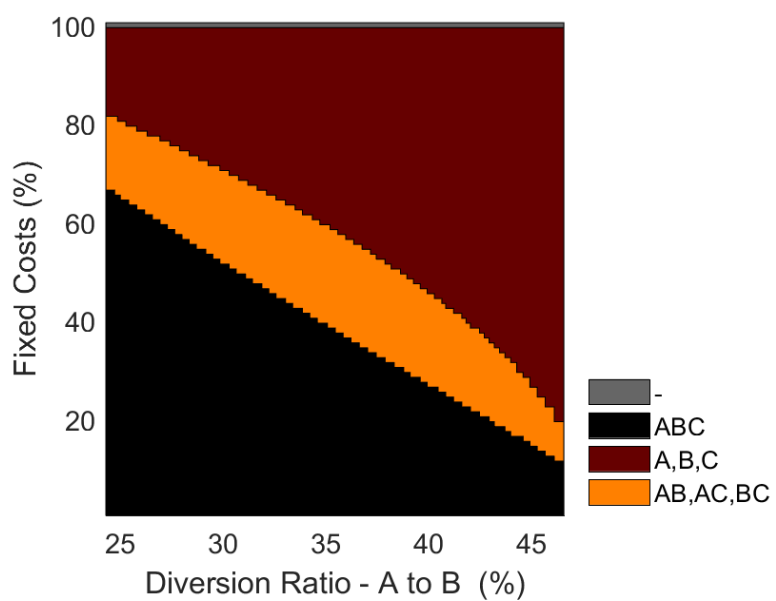

Product differentiation, on the x-axis, is the diversion ratio from $A$ to $B$, derived from the underlying value of $\rho . \rho$ varies from 0 to 1 . Products' fixed costs are shown on the y-axis as a percentage of each product's monopoly variable profits. We summarize market structure by the letters of the products being offered. When multiple equilibrium market structures arise, we list them separated by a comma. See text for detail.

The lower left quadrant of Figure 1 corresponds to all products having low fixed costs and being highly differentiated. Naturally, in such instances all three products are offered in equilibrium. As products become closer substitutes and diversion ratios increase, products compete more closely against each other resulting in lower prices and lower variable profits. Even at moderate fixed costs, it is no longer profitable for all three firms to offer their respective products. Hence, the equilibrium is one in which only two products are offered. As products are symmetric, there are three such equilibria: $A B, A C$, and $B C$. For even higher levels of fixed costs, supporting even two products profitably is not feasible, in particular when they are close substitutes; in any equilibrium, there is at most one product offered. At the topmost part of the figure, when costs are $100 \%$ of monopoly profits, no firm ever offers a product; we assume that in case of ties between offering and not offering a product there is no entry.

How would market structures change if products $A$ and $B$ were owned by the same firm, i.e. the post-merger scenario? A merger creates various conflicting incentives. On the one hand, it decreases pricing pressure as the merged entity can set the price of products $A$ and $B$ jointly and internalize cross-product effects, which results in higher prices and variable profits for all offered products, including those of the non-merging firm. This reduction in pricing pressure incentivizes firms to offer multiple products, as higher variable profits may now offset fixed cost, justifying entry. On the other hand, the merged firm internalizes the business stealing effects that the entry of one product has on the other product's profitability. Despite the higher variable profits that can be obtained post-merger, the merged firm may 
want to cut back on the number of products it offers, decreasing the cannibalization of their own products and saving on the fixed costs of the products being eliminated.

In the following sections we disentagle these incentives, highlighting when they are most likely to be the dominating force driving post-merger market structure. We first explore the incentive to cull products, which is the dominating incentive when pre-merger market structure is $A B C$ and the merger cannot induce additional entry. We then explore how a merger-induced decrease in pricing pressure can result in additional entry, both through rival entry in the case where the pre-merger market structure is $A B$ and potential additional entry by the merged firm itself, focusing on instances when the pre-merger market structure is $A C$. In all instances we assume the merging firm offers product $B$ whenever it is indifferent between offering $B$ or offering $A$. As products are symmetric, this assumption has no real bearing on the analysis.

\subsubsection{A three-to-two merger}

We start by exploring market outcomes post merger when the pre-merger market structure is $A B C$, and two of the three products - products $A$ and $B$ - are under the control of a combined firm post-merger. Figure 2 shows, across four panels, the effects of the merger. The top-left panel shows the post-merger product offering outcomes for various values of fixed costs and product differentiation, akin to Figure 1. The top-right panel shows the change in consumer surplus as a percent of the pre-merger consumer surplus. The bottom panels show the change in firm profits, for the merged firm (bottom-left) and its remaining rival (bottom-right).

The merged firm internalizes the business stealing effects of its product offering decisions on other products in its portfolio. This gives the firms an incentive to reduce product offerings in certain instances. Since products are symmetric and the deterministic portion of consumer preferences for the products is the same in this base case, reducing product offerings means offering just one product. In the top-left panel of Figure 2 we observe how post-merger the merged firm culls product $A$ when fixed costs are near the highest levels that justify a pre-merger market structure with all product being offered. It is when fixed costs are high that products' profits are low, as the fixed cost of offering the product significantly eat into the products' variable profits. By removing product $A$, the merged firm increases the variable profits of product $B$, but loses only the already small profits product $A$ would earn were it to be in the market. When fixed costs are low, the profits earned by product $A$ are large; hence culling the product is no longer a profitable strategy. In these cases the post-merger market structure is the same as the pre-merger one: $A B C$. The possibility of 
Figure 2: Market outcomes conditional on a pre-merger market structure of $A B C$

(a) Post-Merger Market Structure

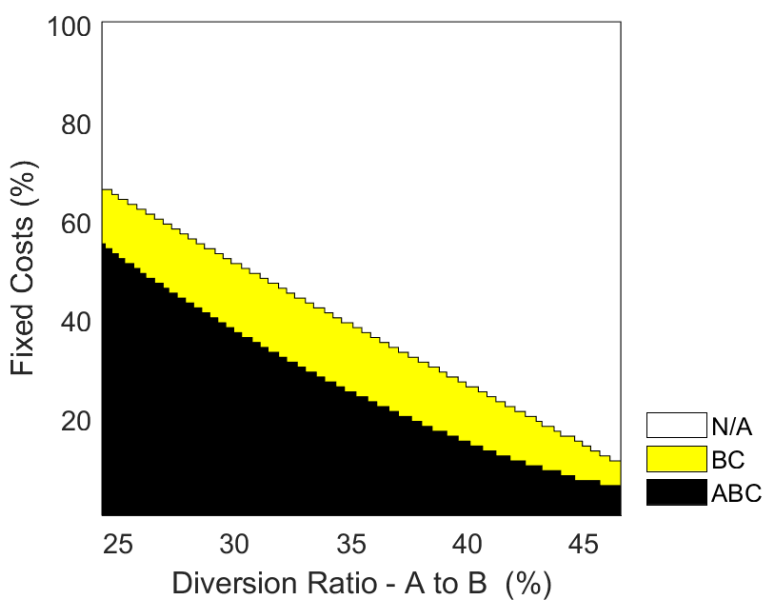

(c) Change in Merged Firm's Profits

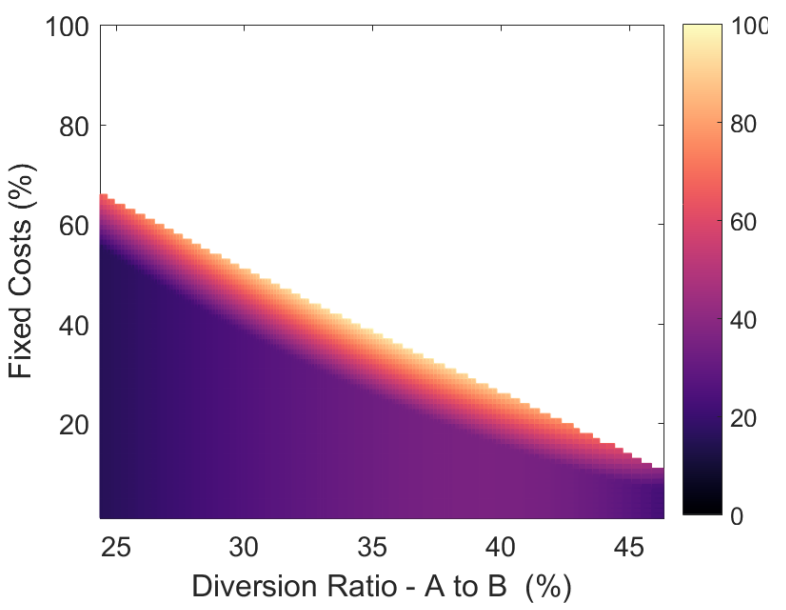

(b) Loss in Consumer Surplus (\%)

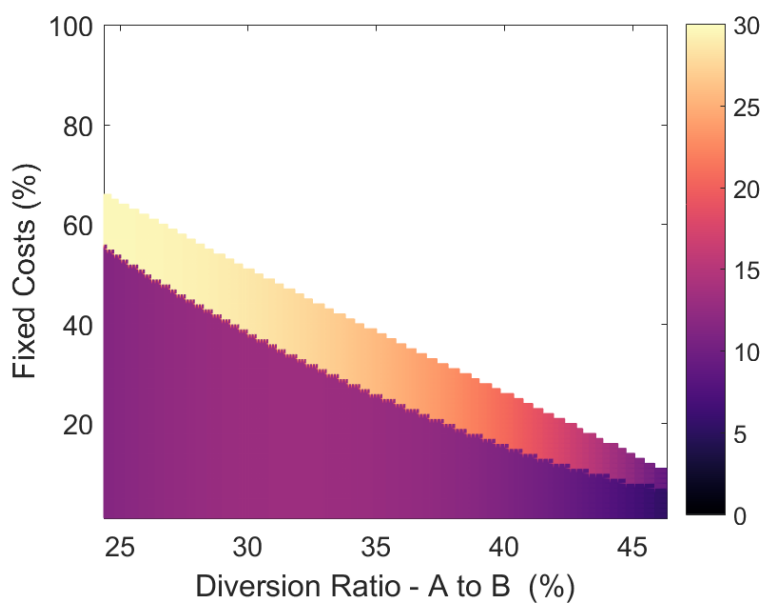

(d) Change in Non-Merging Firm's Profits

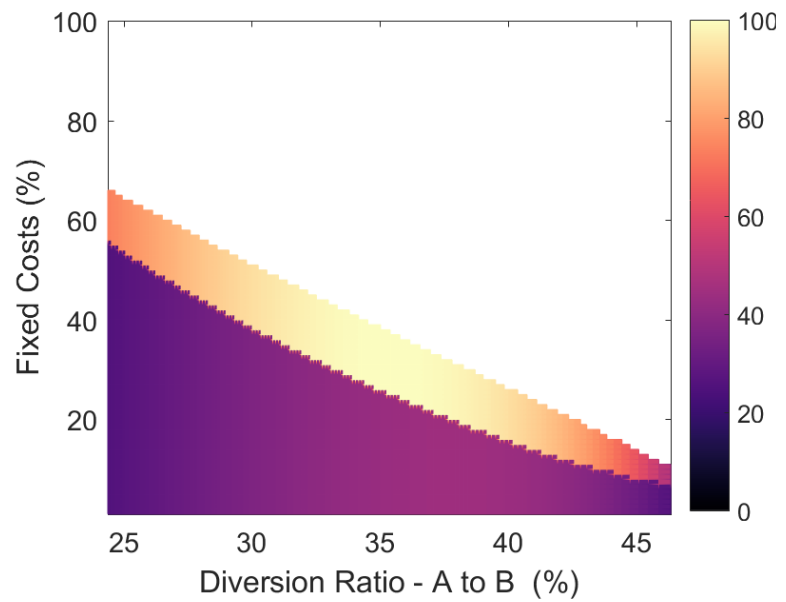

Across panels, we shade in white combinations of fixed cost and travel parameter values that give rise to product offerings that we do not consider in this analysis. See caption in Figure 1 for detail on panel (a) and the axes of all graphs. In panels (c) and (d), we normalize the change in firms' profits by dividing by the largest merger-induced profit change for either the merging parties or the rival across all relevant realizations of fixed costs and the travel parameter.

product variety reductions in more concentrated markets mirrors findings in the empirical literature on excess entry (see, for example, Berry et al., 2016 or Seim and Waldfogel, 2013).

The business stealing effects are largest when products are close substitutes, in the rightmost parts of the graphs. One might expect that, as a result, the merged firm culls product $A$ even at moderate fixed costs if demand is such that the products exhibit high diversion ratios. We do not observe, however, that the height of the $B C$ area increases as one moves to the right of the graph. At high diversion ratios, business stealing is prevalent not only between products $A$ and $B$, but also between products $B$ and $C$. The existence of product $C$ thus limits how much product $B$ 's variable profits increase when culling product $A$. 
Panel (b) in Figure 2 shows the percentage loss in consumer surplus that results from the merger. The graph illustrates that the merger has large effects on consumer welfare in settings where preferences and fixed costs are such that the merged firm chooses to cull product $A$ post-merger. The product withdrawal not only results in reduced competition such that the remaining products command higher prices, but deprives consumers of one variety altogether. Moreover, the consumer surplus loss form the removal of product $A$ is largest in cases where the remaining two products are poor substitutes - on the left-hand side of the graph. Here, the adjustment in product offerings leaves consumers who prefer product $A$ with poor alternatives.

The effects on total welfare are unclear, as there is excess entry prior to the merger. Therefore, when a product is culled in response to the merger, total welfare is positively affected by the reduction in duplicate spending on fixed costs. As described previously, when products are close substitutes there is minimal consumer welfare loss from product $A$ 's removal from the market. Therefore it is in these circumstances when total welfare gain from the merger is largest: spending on fixed costs are reduced and consumers are almost left indifferent.

Traditional price effects of the merger, even without changes in market structure, also result in consumer surplus loss, as evidenced by fixed cost and diversion ratio realizations in the lower area of panel (b) when all three products continue to be in the market after the merger. In this region, consumer surplus loss is highest at moderate levels of differentiation. When products are close substitutes, the presence of product $C$ limits the ability of the merged entity to increase price, despite the decrease in pricing pressure. Similarly, when products are poor substitutes - in the left-hand side of the graph - internalizing business stealing by the merged firm changes prices little. It is for intermediate diversion ratios between 30 and $35 \%$ that the merger grants the merging parties the ability to significantly raise prices, affecting consumer welfare negatively. Importantly, total welfare always decreases with the merger when product offering is not adjusted, as consumers are always hurt from higher prices and firms do not reduce costs from over entry.

The bottom two panels of Figure 2 show the change in firms' profits. For the merged firm, we compare the profit post-merger to the sum of the products' standalone profit premerger. As for some combinations of fixed cost, $g_{i}$, and travel parameter, $\rho$, the pre-merger profit of either the merging parties or their rival is arbitrarily close to zero, a comparison of percent changes in profitability across $g_{i}$ and $\rho$ is not meaningful, as it masks the very small base giving rise to the large percent change. Instead, we normalize a given change in profit by dividing by the largest profit increase achieved across all relevant $g_{i}$ and $\rho$ and across all firms. Panel (c) shows that the merger always results in a profit gain for the 
merging firms, as additional entry by rivals is not feasible -i.e. $C$ is already offered premerger. However, the largest profit increases occur when product $A$ is culled and when, prior to the merger, firms are almost indifferent between offering a product or not. The latter occurs for $g_{i}$ and $\rho$ values that make up the boundary where pre-merger, firms are just willing to offer all three products. The gain in profit from culling a product can be up to 2.5 times larger than the profit increase that the merged firm can achieve solely through joint pricing, i.e. joint pricing when holding market structure fixed generates profit increases of only $40 \%$ of the largest profit increases when a product is culled. These results suggest that coordination on product choice, more so than on pricing, can be an effective way for firms to benefit from a merger. More importantly, as firms benefit most from mergers that result in reductions in offered products, it is these types of mergers that firms are most likely to pursue. As these are also the mergers that result in the largest losses to consumer welfare, we caution against relying solely on price-only merger simulations in settings such as retail or telecommunications where product offering adjustments are common.

Finally, the non-merging firm benefits most from the merger: it either faces fewer competing products or higher prices on existing products. Both effects result in the highest profit increments when products are moderate substitutes, i.e. at intermediate diversion ratios. Here products are close enough so that decreased pricing pressure and a decreased product offering result in significantly higher prices and/or sales, but far enough that competition with the remaining product does not erode profits.

\subsubsection{A merger between duopoly incumbents}

In this subsection we explore the effects on product offering decisions and prices when the pre-merger market structure is $A B$, reflecting the merging of two existing players when there are potential entrants. Cabral (2003) shows how a merger that reduces pricing pressure can induce entry, ultimately resulting in profit losses for the merging parties. Cabral (2003) assumes entry costs are sunk; as a result, the merged firm does not cull products after the merger. In our setting entry costs are fixed but not sunk, so the merged firm can mitigate, and in some cases avoid altogether, the losses from additional entry by culling their own products. Moreover, as above, the merged firm may have an incentive to cull products regardless of rival entry or of reductions in pricing pressure. Experts have cited such considerations in grocery store mergers, such as the 2009 merger between Whole Foods and Wild Oats where the government argued that store reductions would be likely. ${ }^{6}$ In response to such a reduction in offerings, other industry participants may increase their own

$6 \quad$ See Kevin Murphy's expert report (Murphy (2007)). 
product offerings. The net effect would be weakly reduced total product offerings, following the same rationale underlying competition in strategic substitutes more generally.

Figure 3: Market outcomes conditional on a pre-merger market structure of $A B$

(a) Post-Merger Market Structure

Symmetric Fixed Costs

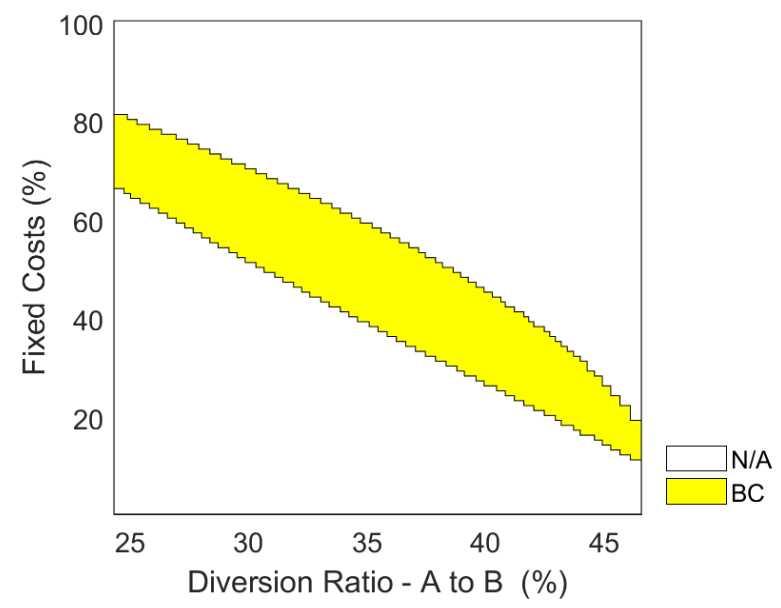

(c) Loss in Consumer Surplus (\%)

Asymmetric Fixed Costs

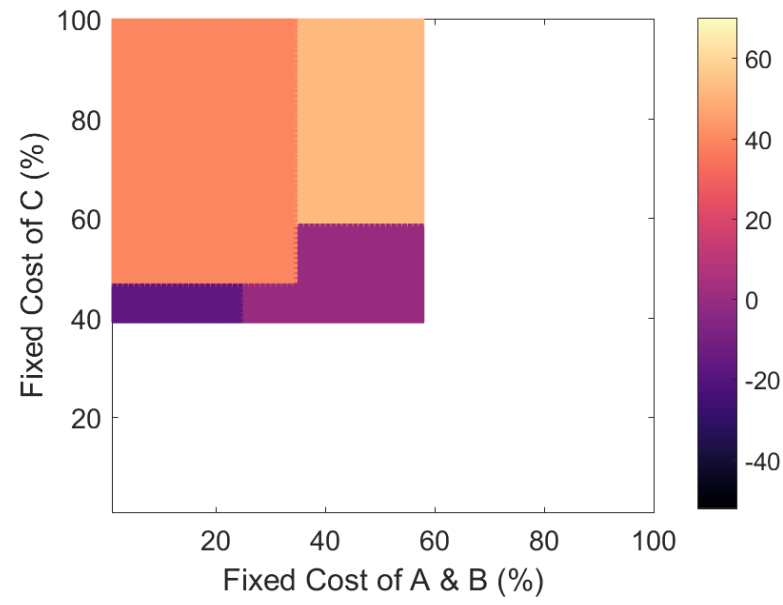

(b) Post-Merger Market Structure Asymmetric Fixed Costs

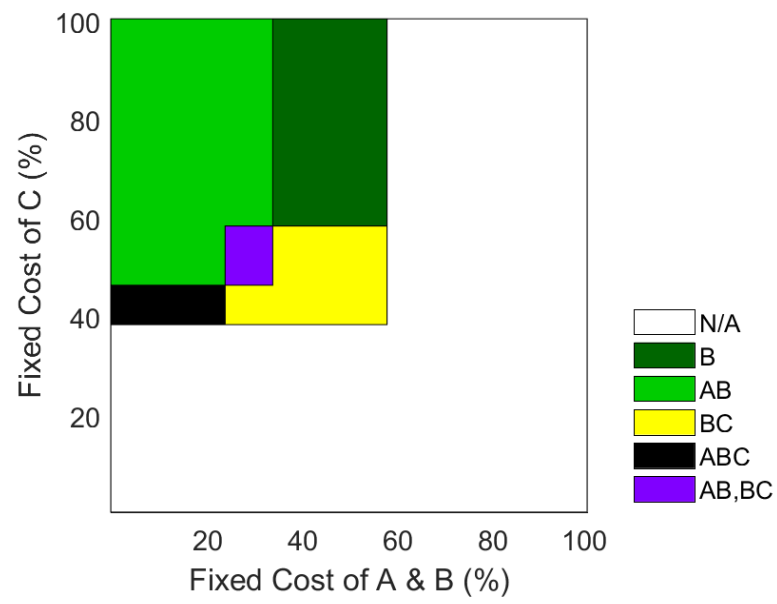

(d) Change in Merged Firm's Profits Asymmetric Fixed Costs

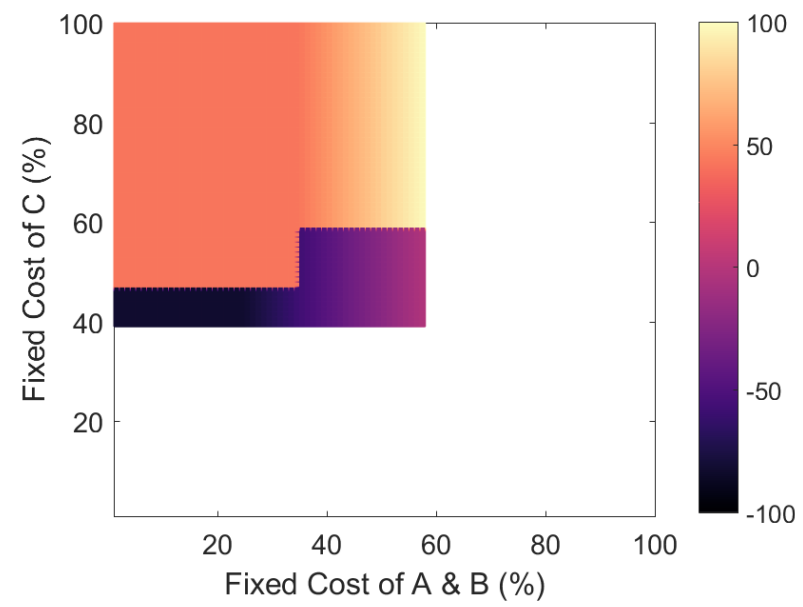

Fixed costs shown as a percentage of each products' monopolist variable profits, $\bar{\pi}$. In panels (b) through (d) we set $\rho$ at 0.72 , which implies a diversion ratio from $A$ to $B$ of $35 \%$. In panel (d) we normalize the change in firms' profits by dividing by the largest merger-induced profit change for the merging parties across all relevant realizations of fixed costs. See caption in Figure 1 for detail.

To analyze the effects of a merger with potential entry, panel (a) in Figure 3 shows the post-merger market structure that arises for fixed cost and travel parameters that result in only products $A$ and $B$ being offered pre-merger. Note that these parameter values do not yield a single equilibrium; Figure 1 illustrates that any of the three combinations of two products entering is an equilibrium for such parameter value combinations. We select the 
$A B$ equilibrium, and consider firms' incentives to change their product offering post merger. For these parameter values, there is a unique post-merger equilibrium in which the merging parties cull product $A$ and the non-merging party enters with product $C$. There is not any effect on either consumer surplus or total welfare as products are symmetric and both preand post-merger market structures consist of two competing products; the merger simply transfers profit from the merged firm to its new rival.

Panel (a) considers the simplest case when all products have the same fixed cost values. In the remaining panels in Figure 3 , we take a more nuanced approach in allowing the merged firm and its rival to differ in the fixed cost of offering products. We fix the travel parameter $\rho$ at an intermediate level that generates a diversion ratio of $35 \%$. We then vary product $C$ 's fixed cost, from 0 to the largest possible fixed cost value, which as above corresponds to $C$ 's variable profit when it is the only product in the market, $\bar{\pi}$. We similarly vary fixed cost levels for products $A$ and $B$, but continue to vary them symmetrically. In panels (b) through (d), we plot $C$ 's fixed cost on the y-axis and the fixed cost of products $A$ and $B$ on the x-axis. We continue to condition on a pre-merger market structure of $A B$. As a result, only fixed cost combinations in the north-west corner of the panels are relevant: when products $A$ and $B$ have sufficiently low fixed costs to be offered pre-merger, but product $C$ has high fixed cost and is out of the market pre-merger. Panel (b) shows post-merger market outcomes; panel (c) the percent loss in consumer surplus due to the merger; and panel (d) the merger-induced gain in the merged firm's profits, relative to its largest possible gain.

More interesting outcomes arise in this asymmetric cost scenario. Panel (b) illustrates that product $C$ chooses to enter post-merger regardless of the merging parties' offering decision provided its fixed cost is at the low end of the relevant fixed cost range, between $40 \%$ and $48 \%$ of its highest possible variable profit level, $\bar{\pi}$. When product $C$ 's fixed cost is in this range and $A B$ 's fixed costs are low - at less than $25 \%$ of their highest possible variable profit $\bar{\pi}$ - the merging parties do not have an incentive to cull products. Variety thus increases post-merger. This results in an increase in consumer surplus and a decrease in the merged firm's profits: C's entry depresses prices, increases consumers' options, and steals sales from the merging parties. This is precisely the effect discussed by Cabral (2003). However, as costs are fixed and not sunk, as assumed in Cabral (2003), the merged firm may offset the profit loss from $C$ 's entry by culling a product and saving on fixed costs. The merging parties find this optimal when such fixed costs are above $25 \%$ of $\bar{\pi}$, resulting in a post-merger market structure of $B C$. As in the symmetric fixed cost case, the merger then has no effect on consumer welfare as preferences for products are symmetric. Reducing product offerings largely, but not entirely, cushions the merging parties against profit losses from the entry of the rival $C$. For example, when the merging parties' fixed costs are $40 \%$ 
of $\bar{\pi}$, the change in the merged firm's profits is -0.059 units if the post-merger market structure is $B C$ and -0.086 units if the market structure is $A B C$, an increase in losses of $45 \%$. These comparisons also illustrate the limited incentive to merge when a rival stands ready to enter after the merger due to relatively low product offering costs.

Different incentives are at play when product $C$ 's cost are at intermediate levels, between $48 \%$ and $58 \%$ of $\bar{\pi}$. In this situation $C$ does not find it profitable to enter when $A$ and $B$ also enter, despite the price increase generated by the merger. For a subset of parameter values with such intermediate fixed costs for $C$ and intermediate fixed costs for the merging parties, between $[25 \%, 35 \%]$ of $\bar{\pi}$, the post-merger game has two equilibria, where one equilibrium market structure is $A B$ and the other is $B C .^{7}$ If $A$ and $B^{\text {'s }}$ fixed costs exceed these intermediate levels, however, the merging parties have an incentive to cull $A$, saving on the fixed cost and driving up $B$ 's variable profits. The culling of $A$ entices $C$ to enter, resulting in a post-merger market structure of $B C$, with a zero effect on consumer welfare and a net loss in the merged firm's profits, of up to 60 points. The merging parties thus have an incentive to cull $A$ regardless of $C$ 's entry decision, and $C$ enters only because of this culling. In contrast, when $C$ 's fixed costs are low, as discussed in the previous paragraph, it has an incentive to enter regardless of the merging parties' product offering choice, and the merging parties remove $A$ only in response to $C$ 's entry.

Finally, if $C$ 's fixed costs are high, it plays no role as a potential entrant. The merging parties cull $A$ if their own fixed costs are high, and this culling results in a significant loss of consumer welfare (52\%). If $A$ and $B$ 's fixed costs are low, the two products remain in the market. Consumer welfare loss is still significant at up to $40 \%$ due to the price increase resulting from the two-to-one merger. Similarly, the merged firm's profit increase is most significant when culling one product.

The above analysis identifies feasible fixed cost realizations for which the merged firm chooses to remove a product, which in turn incentivizes the non-merging firm to enter, leading to a loss of profit for the merged firm. One may worry that this result is an artifact of considering a static, simultaneous-move game; a richer dynamic model might not have such a prediction. In the appendix we consider a simple sequential move game that captures these dynamic incentives and shows that this possibility is not purely an artifact of the simultaneous move nature of our setup. The merged firm chooses which products to offer first. Then, after observing the merged firm's product offering, firm $C$ decides whether to offer its product. Lastly, given these offering decisions firms simultaneously set prices. We

$7 \quad$ In calculating the merger-induced change in consumer and producer surplus (panels (c) and (d) of Figure 3), we assume the $A B$ market structure arises post-merger whenever it is one of the post-merger equilibrium market structures, matching the pre-merger market structure. 
find that when $C$ 's fixed cost is high, the merging parties indeed retain both products in the sequential move game, even when they would cull one in the simultaneous move game. By doing so, they deter $C$ from entering. However, when $C$ 's fixed cost is low, the decreased pricing pressure between the two products of the merged firm raises prices sufficiently that $C$ finds it profitable to enter. Anticipating $C$ 's entry, the merging parties choose to cull one of their products to limit the profit losses from $C$ 's entry. Even when the merging incumbents are able to anticipate entry, their incentive to retain both products is limited when a low-cost potential entrant stands ready to come in under the more concentrated market structure.

\subsubsection{A merger between an incumbent and a potential entrant}

In this subsection we return to the simultaneous move game and explore the effects of a merger in a duopoly market structure, where one incumbent merges with a potential entrant. In particular, we consider whether higher prices from decreased pricing pressure could induce entry of that potential entrant post-merger.

We begin by conditioning on fixed cost and travel parameter values such that two of the three potential products choose to operate in equilibrium, pre-merger. Since the products are symmetric, the identities of these products are not pinned down uniquely. We arbitrarily assume that the pre-merger market structure consists of $A$ and $C$ and consider, as above, a merger between product $A$ and potential entrant $B$. Analogously to Figure 3 , we display the results of such a merger in Figure 4. Panels (a) through (c) show the post-merger market structure, and panel $(\mathrm{d})$ displays the effect of the merger on the merged firm's profits.

Panel (a) shows that, when fixed costs are symmetric, the post-merger market structure is $B C$ for all relevant realizations of fixed costs and the travel parameter. As products $A$ and $B$ are identical in demand and in costs, ${ }^{8}$ this is equivalent to stating that there is no change in the equilibrium market structure due to the merger for the specified parameter values. Fixed costs are moderate in this scenario as two products could profitably enter pre-merger but not three. Adding a third product post-merger, despite higher prices under common ownership than if only two products compete, does not generate sufficient incremental profit to offset a second fixed cost and A's lost variable profit. The reduction in pricing pressure with a merger thus does not induce entry.

As above, we consider whether these conclusions change when we allow the products to have asymmetric fixed costs. We hold the travel parameter fixed at 0.72 , corresponding to a diversion ratio from $A$ to $B$ of $35 \%$, and consider an asymmetry in fixed costs between the two products, $A$ and $B$, of the merged firm, assuming $C$ 's fixed costs are so low that it

$8 \quad$ We have implicitly assumed that the merged firm offers product $B$ when indifferent between offering product $A$ or offering product $B$. 
Figure 4: Market outcomes conditional on a pre-merger market structure of $A C$

(a) Post-Merger Market Structure

Symmetric Fixed Costs

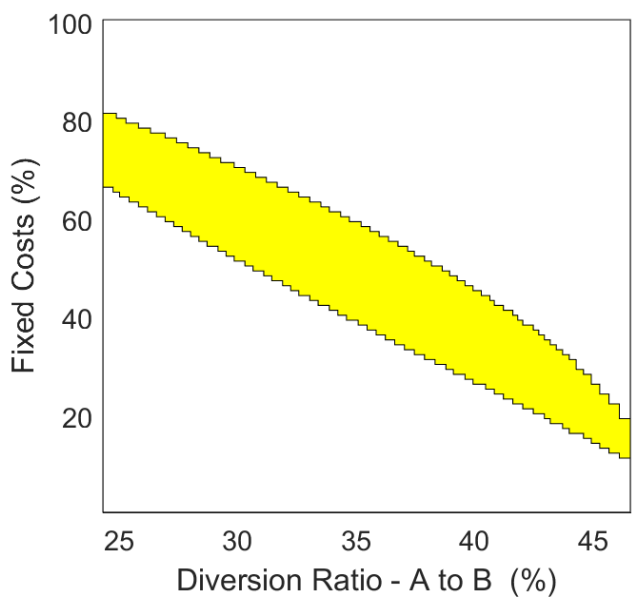

(c) Post-Merger Market Structure

Asymmetric Fixed Costs - $A$ always offered

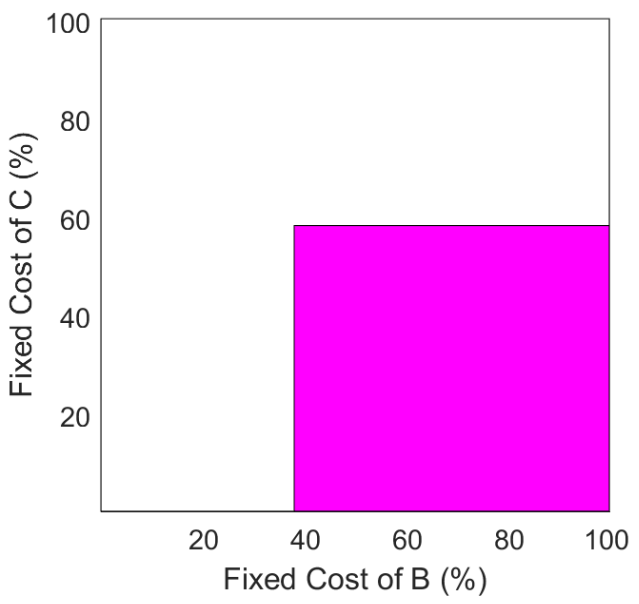

(b) Post-Merger Market Structure

Asymmetric Fixed Costs - $C$ always offered

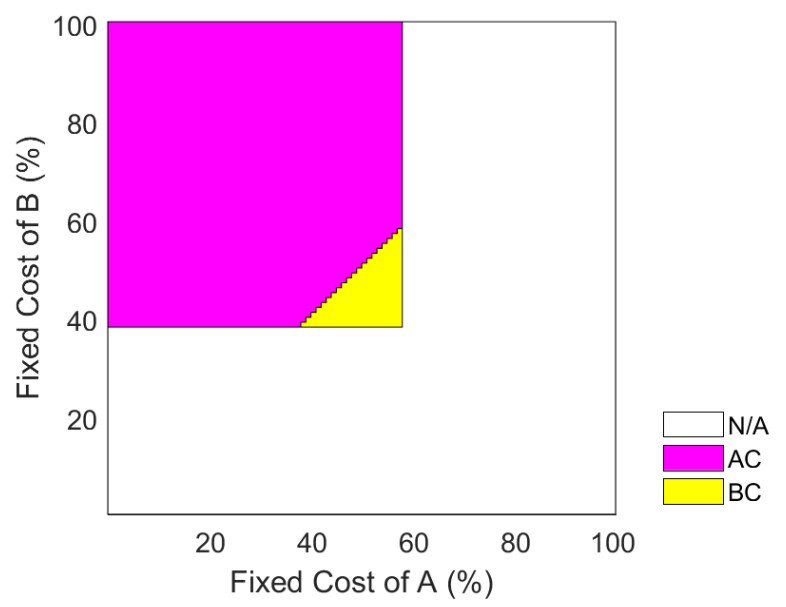

(d) Change in Merged Firm's Profits

Asymmetric Fixed Costs - $C$ always offered

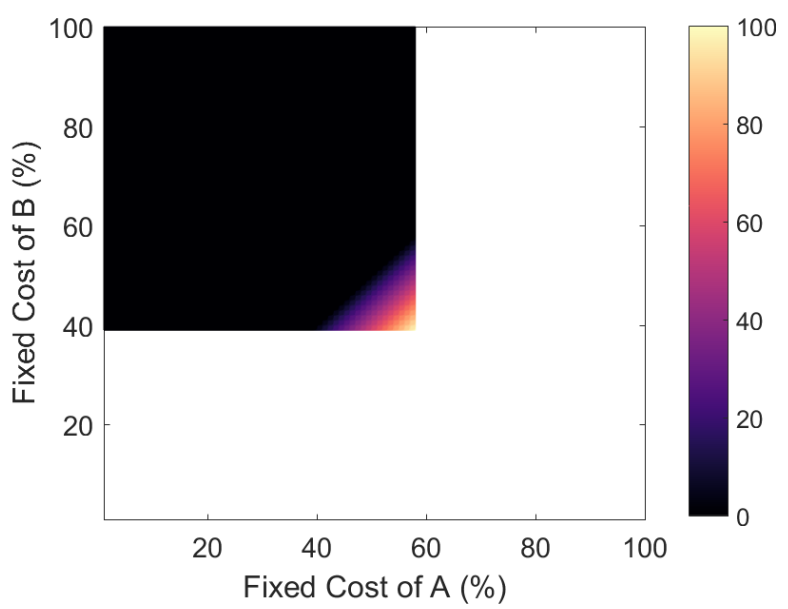

Fixed costs shown as a percentage of each product's monopoly variable profits, $\bar{\pi}$. Panels (b)-(d) display market outcomes as a function of two of the three products' fixed costs, holding the offering choice of the third product constant. We set $\rho$ at 0.72 , which implies a diversion ratio from $A$ to $B$ of $35 \%$. In panel (d), we normalize the change in firms' profits by dividing by the largest merger-induced profit change for the merging parties across all relevant realizations of fixed costs. See caption in Figure 1 for detail.

always enters. Panel (b) shows the resulting market outcomes in this case, and panel (d) shows the change in the merged firm's profits.

Not surprisingly, post-merger, the merged firm offers $A$ whenever $A$ 's fixed cost are lower than $B$ 's. However, when $B$ 's fixed cost are lower than $A$ 's, the firm has a strict incentive to replace $A$ with $B$, as both generate the same variable profits but one has a lower fixed cost than the other. This switch does not affect consumer surplus: all products are identical 
beyond their fixed cost. It does, however, increase the merged firm's profits, especially when $B$ 's fixed cost is significantly lower than $A$ 's.

Panel (c) displays post-merger market outcomes under a different set of fixed cost values. In this panel, we graph the fixed costs of the potential entrant, $B$, against the fixed costs of the non-merging incumbent, $C$, holding product $A$ 's fixed costs at sufficiently low levels that it is always profitable. Surprisingly, there are no fixed cost realizations such that the firms offer all three products post-merger. Even when $A$ 's fixed cost are zero and $B$ 's fixed cost are as low as possible (i.e. $38 \%$ of $\bar{\pi}$ ), the merged firm prefers to offer only $A$ over offering both products and incurring $B$ 's moderate fixed cost. Although not shown in Figure 4, this pattern of offering only one product holds for all travel parameter values. Thus, regardless of the degree of differentiation and fixed costs, the merger does not increase variable profit across the portfolio sufficiently for the merged firm to increase its variety offerings and introduce an additional product.

In summary, these simulations suggest that the ability of the merging parties to optimize product offerings over their full portfolio is frequently at least as valuable as the ability to price jointly. In particular when fixed costs are high, a merger has the potential to reduce variety as a smaller product portfolio increases variable profit for the remaining products and reduces fixed costs across the portfolio, outweighing the incremental variable profit gains from additional varieties. From the consumer's perspective, this amplifies welfare losses well beyond those associated with the merger's price effects. Including predictions of these effects will be particularly important when regulatros anticipate post-merger product portfolio changes. Moreover, we find limited support for the idea that the reduced pricing pressure due to a merger can induce additional entry and increase product variety, either through the merging parties' own efforts or through the entry of a rival. When it does occur, the entry of a rival post-merger frequently goes hand-in-hand with reduced product offerings by the merging parties, an outcome that persists even if the merging parties have a firstmover advantage and can commit to their product offerings before the rival. These results highlight the value of modeling both product offering and price adjustments post-merger: depending on the circumstances, the policy recommendations regarding mergers may dffer substantially that when based on price effects alone.

\subsection{A Case Study: The Premium Ice Cream Market}

A downside to the symmetric setting with equidistant products is that consumers in aggregate are not sensitive to which subset of two products firms offer post-merger. The model we employ in this paper could, however, apply to a wide range of more realistic settings than 
the symmetric product setup. To highlight the model's flexibility and consider the role of more nuanced differentiation between products on profit and consumer welfare, we calibrate the parameters of the model to real data. Based on prior related work (Draganska et al. 2009), we use data from the US ice cream industry and focus on the premium vanilla category, which fits within the confines of the proposed model in several important ways. There are two leading national suppliers - Breyers and Dreyers - and various regional players that we collapse into a "composite" third firm. ${ }^{9}$ Ice cream products differ both horizontally - as in the above case - and vertically as the national brands may, for example, have reputational or product quality advantages over the smaller regional players.

Table 2: Demand and Variable Cost Parameters - Ice Cream Setting

\begin{tabular}{rccccccc}
\hline \multicolumn{3}{c}{ (a) Product Specific Values } & & & (b) Common Values \\
& $\mathrm{B}$ & $\mathrm{D}$ & $\mathrm{C}$ & & & \\
${$\cline { 1 - 3 }$\left(\mu_{F}\right)} }$ & -0.24 & -0.42 & -0.40 & & Price Coefficient $(\alpha)$ & -0.39 \\
Variable Cost $(c)$ & 2.52 & 2.27 & 2.37 & & T1EV Scale $(\sigma)$ & 0.125 \\
Fixed Costs $\left(g_{i}\right)$ & {$\left[0, \bar{\pi}_{B}\right]$} & {$\left[0, \bar{\pi}_{D}\right]$} & {$\left[0, \bar{\pi}_{C}\right]$} & & Travel Parameter $(\rho)$ & 0.17 \\
& & & & & Market Size $(M)$ & 1.0 \\
\hline
\end{tabular}

Values calibrated using observed market shares, observed prices, and estimated elasticities shown in Equation 12

Web Appendix A presents a flexible model of demand for vanilla ice cream flavors and the details for estimating this model. The data consists of monthly units sold and revenue of 3.5-4 pint containers of vanilla ice cream, spanning 63 US cities from July 2003 to June 2005 for each of three brands: Breyers (B), Dreyers (D), and the above composite brand (C). We use the estimated demand system to calculate average brand-level own and cross-price elasticities across all markets and months that share a common portfolio of vanilla flavors - the modal one. ${ }^{10}$ The estimated elasticities, together with sales-weighted average brandlevel prices and market shares, allow us to calibrate realistic preferences for the three-product model from section 3.1, aggregating each brand's vanilla sales into a single product. These preference and pricing summary statistics are:

$952 \%$ of markets have a single regional player with more than a $5 \%$ share of premium vanilla ice-cream sales. Thus, for most markets, the composite firm simply represents the regional brand. The model we propose can easily accommodate additional competitors, but we chose to collapse them into a single firm in the remaining markets to simplify the graphical representation of our results. As a result, our calibrated parameters may not accurately reflect the mean attractiveness of individual brands that we combine across markets and may overstate the true market power exerted by the regional player.

10 As the flavors offered differ across markets and time, elasticities differ due to entry and exit. By only considering market-months with the same flavor offerings, such differences do not affect the average elasticities. To calculate the average elasticity over the most market-months possible, we choose the product portfolio that is most commonly offered across market-months. 


$$
\begin{aligned}
& s_{B}=5.6 \% \quad s_{D}=3.4 \% \quad s_{C}=3.1 \% \\
& p_{B}=\$ 3.75 \quad p_{D}=\$ 3.47 \quad p_{C}=\$ 3.57
\end{aligned}
$$

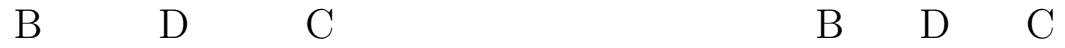

$$
\begin{aligned}
& \eta=\begin{array}{l}
\mathrm{B} \\
\mathrm{D} \\
\mathrm{C}
\end{array}\left[\begin{array}{ccc}
-3.05 & 0.10 & 0.09 \\
0.18 & -2.89 & 0.09 \\
0.18 & 0.10 & -2.99
\end{array}\right] \quad D R=\begin{array}{l}
\mathrm{B} \\
\mathrm{D} \\
\mathrm{C}
\end{array}\left[\begin{array}{ccc}
N A & 3.57 & 3.27 \\
5.77 & N A & 3.18 \\
5.75 & 3.46 & N A
\end{array}\right]
\end{aligned}
$$

where $s$ denotes average market shares, $p$ prices, and $\eta$ the matrix of own and cross-price elasticities, and $D R$ the matrix of diversion ratios (from row brand to column brand). We rely on them to calibrate the price coefficient $(\alpha)$, mean utilities $\left(\mu_{F}\right)$, and the travel parameter $(\rho)$ in $\Sigma_{F}$. We match predicted shares and elasticities implied by the model in Equations 3 and 7 to the observed values in the data in Equation 12. As there are only five parameters but twelve preference moments from the data, we calibrate the parameters by minimizing a weighted sum of squared differences between the predicted values and the observed values, weighing share and elasticity predictions such that half of the identifying variation arises from elasticities and the other half from mean market shares. We set the T1EV scale parameter $\sigma$ to $1 / 8 .{ }^{11}$ Lastly, we assume optimal Bertrand-Nash pricing by firms to calibrate marginal costs that are consistent with the observed prices and preferences. This implies that $c_{j}=p_{j}\left(1+1 / \eta_{j j}\right)$ where $\eta_{j j}$ is the own price elasticity.

Table 2 shows the resulting demand and cost parameters. We highlight three points. First, Breyers is the preferred product, with a mean utility of -0.24 compared to a mean utility of -0.42 for Dreyers and of -0.40 for the composite brand. Given a price coefficient of -0.39 , Breyers can charge the average consumer a $46 \phi$ premium over Dreyers and keep such consumer indifferent between the two. Hence, Breyers is the strongest product in terms of demand. Second, Breyers also has the highest variable cost, 25中 higher than Dreyers and 15 higher than the composite brand. Given the utility premium is larger than the variable cost difference, it is likely that Breyers is also the stronger product in terms of profitability - absent fixed costs. Third, the composite brand has a slightly higher innate demand than Dreyers, commanding a $5 \mathrm{\phi}$ premium for the average consumer. However, it also has a $10 \mathrm{\phi}$ higher variable cost than Dreyers. Taken together, the composite brand offers a comparable alternative to Dreyers.

As in section 3.1, we now use these preferences and cost estimates to consider the effects

11 We fix $\sigma$ to be a low value to be able to investigate the role of the degree of substitutability between products on merger outcomes. A large $\sigma$ limits how close products can be to each other. 
of the same merger we studied above. We focus on the product offering and pricing effects of a hypothetical merger between the strong brand, Breyers, and Dreyers. We again explore the effects of the merger conditional on select pre-merger market structures and variation in these effects depending on the travel parameter and fixed cost values. To be consistent with the previous graphs, we plot each firms' fixed costs as a percentage of the maximum achievable variable profits the product achieves as a monopolist. In contrast to the previous section, however, this maximum value differs across the three products, and therefore a plotted value of, say, 60 percent, represents different fixed costs for each of the three products. Alternatively, we could have plotted fixed costs in absolute terms, acknowledging that some products might not ever be offered at the largest plotted costs.

\subsubsection{A three-to-two ice cream merger}

Figure 5 shows the effect of a merger between Breyers and Dreyers when all three brands are active prior to the merger. Qualitatively, the effects are very similar to those in subsection 3.1.1 when fixed costs are high, the merged firm culls a product, resulting in higher profits for everyone and a significant consumer surplus loss. Quantitatively, the effects are different, however, reflecting the differentiation between the products of the merged firm. For the calibrated parameter values the merging party chooses to cull the Dreyers brand. In terms of demand, Dreyers is the weaker of the two brands. As a result, the gross consumer welfare loss from the reduction in offerings and price adjustments is between 15 and 30 percent, depending on the degree of substitution. In contrast, the consumer surplus loss when firms continue to offer all products, and the merger only causes price effects, is at most 12 percent. As above, we also find that the ability to cull products has significant additional profit implications for the merged firm. However, in contrast to the symmetric case where the profit gain from product portfolio adjustments was at most two times the profit gain from adjusting price alone, here the profit gains when a product is culled are up to three times larger than when products are not culled, possibly due to the lower quality of the composite product. This highlights the value of a careful empirical analysis of the incentives and implications of product portfolio adjustments with changes in concentration.

\subsubsection{A merger between two duopoly ice cream incumbents}

The downside of the symmetric model used in the prior section is that consumers value all products equally. Hence a change in market structure from $A B$ to $B C$ leaves consumers unaffected. With the calibrated ice cream parameters, however, consumers are not indifferent between a choice set of Breyers and Dreyers and a choice set of Dreyers and the composite 
Figure 5: Market outcomes conditional on a pre-merger market structure of $B D C$ (Breyers, Dreyers, and Composite)

(a) Post-Merger Market Structure

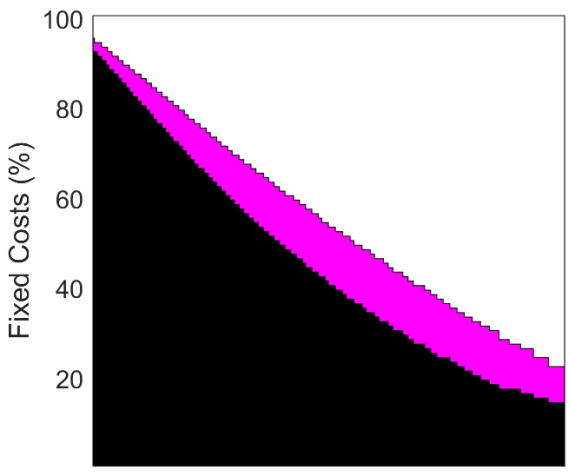

$\begin{array}{lllllll}5 & 10 & 15 & 20 & 25 & 30 & 35\end{array}$

Diversion Ratio - Breyers to Dreyers (\%)

(c) Change in Merged Firm's Profits

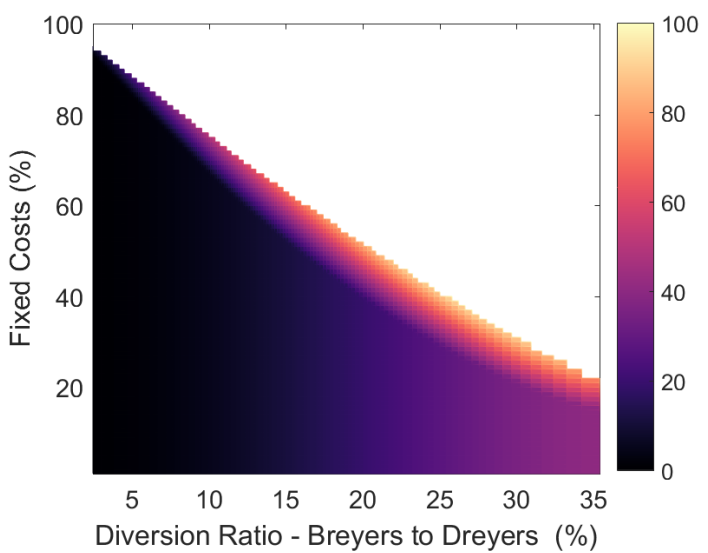

(b) Loss in Consumer Surplus (\%)

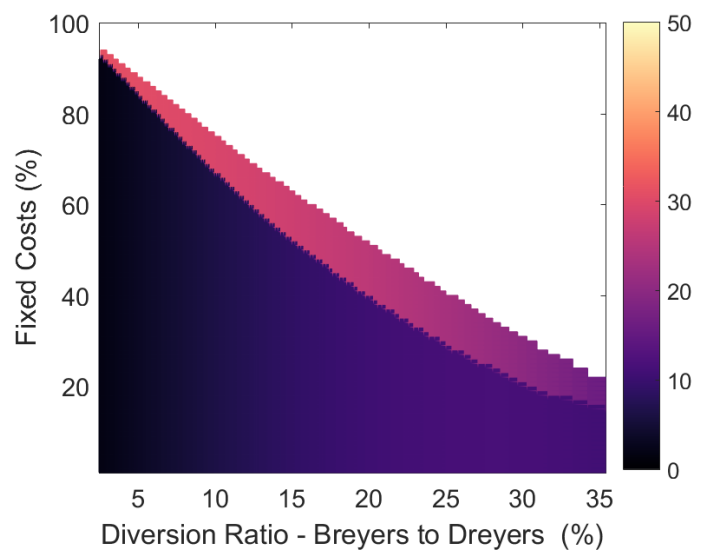

(d) Change in Non-Merging Firm's Profits

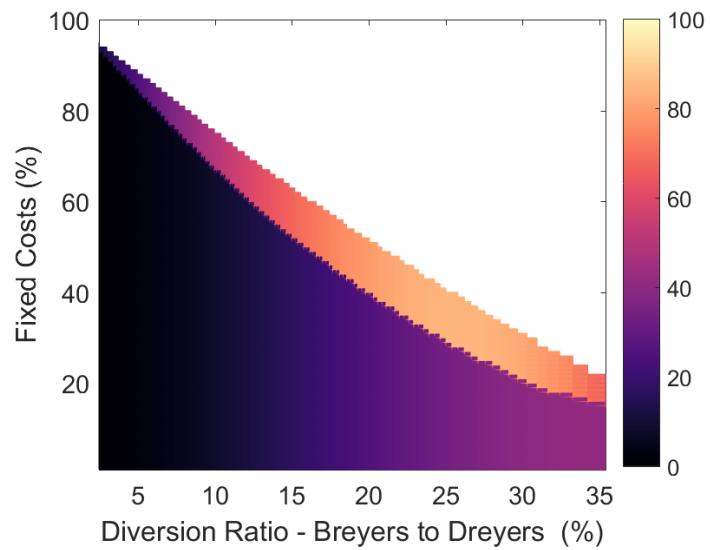

The diversion ratios from Breyers to Dreyers, shown on the x-axis, are derived from underlying values of $\rho$, varied from 0 to 1. The remaining demand and cost parameters are set at their values in Table 2 Fixed costs shown as a percentage of each brands' monopolist variable profits, $\bar{\pi}_{B}, \bar{\pi}_{D}$, and $\bar{\pi}_{C}$. In panels (c) and (d), we normalize the change in firms' profits by dividing by the largest merger-induced profit change for either the merging parties or the rival across all relevant realizations of fixed costs and the travel parameter. See caption in Figure 1 for detail.

brand, and we expect such differences between products to arise in most settings. In this subsection we therefore explore the implications of vertical differentiation on incentives to enter post-merger and the associated consumer welfare effects. For simplicity, we set the travel parameter at 0.72, which implies a diversion ratio from Breyers to Dreyers of 19\%, and condition on fixed costs that give rise to a pre-merger market structures in which Breyers and Dreyers offer one product each and the composite brand offers none, i.e. a $B D$ permerger market structure.

The key point we would like to illustrate with this merger simulation is that there is a myriad of feasible market outcomes that can arise post-merger, and that these can have 
Figure 6: Market outcomes conditional on a pre-merger market structure of $B D$

(c) Post-Merger Market Structure

Asymmetric Fixed Costs - Composite brand never offered (d) Post-Merger Market Structure Asymmetric Fixed Costs
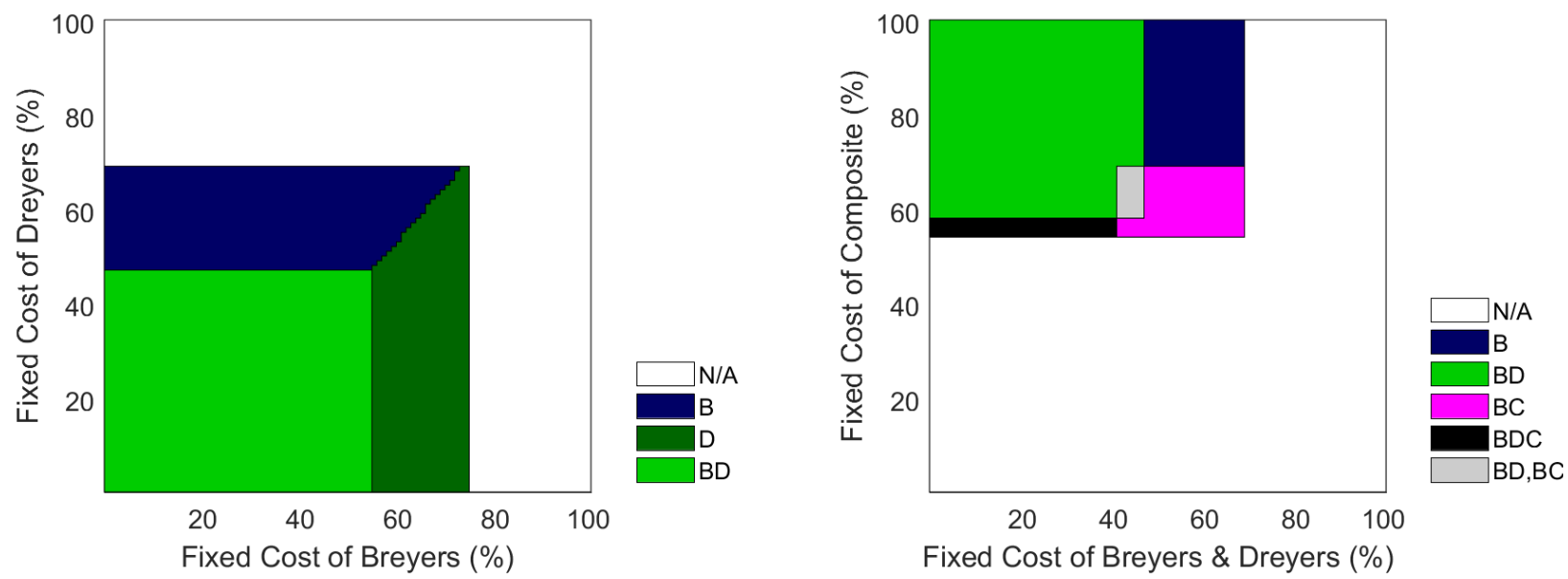

Fixed costs shown as a percentage of each brand's monopoly variable profits. We set $\rho$ at 0.72 , which implies a diversion ratio from $B$ to $D$ of $19 \%$. See caption in Figure 5 for detail.

vastly different effects on consumer welfare and firm profits. Therefore, one cannot make an assesment of which products would be offered in a post-merger scenario without a deep understanding of the merging firms' fixed costs in addition to products' demand.

To illustrate these ideas, Figure 6 shows the post-merger market structures for various fixed cost values, conditioning on fixed costs that are consistent with the pre-merger market structure. Panel (a) plots on the x-axis Breyer's fixed costs, on the y-axis those of Dreyers, and assumes the composite brand's fixed cost are so high it is never offered post-merger. Similar to the symmetric firm case, the merging firm culls one of the two brands when costs are high. Importantly, the firm chooses to cull the high demand product, Breyers, when this brands' fixed costs are high relative to Dreyers. Not surprisingly, in the extreme case in which Dreyers' fixed costs are extremely low (bottom of the plot), it is never in the firms' best interest to cull Dreyers' as there is no cost savings from doing so. The choice of which product is culled affects consumers deeply. Table 3 shows the percentage change in consumer surplus for various per-merger and post-merger market structures. Here, one observes that when Dreyers' is the culled product, consumer welfare drops by 44 percent; in contrast, when Breyers' is culled the loss is much larger: 53 percent.

The second panel of Figure 6 plots post-merger market outcomes, varying the composite brands' fixed cost, on the x-axis, and varying Breyer's and Dreyer's fixed cost jointly on the $\mathrm{y}$-axis. As the composite brand is not offered pre-merger, its fixed cost cannot be too small. However, there is a range of values in which the Composite brand's costs are moderate and the 
Table 3: Merger Induced Changes in Market Outcomes - Ice Cream Setting

\begin{tabular}{rcccccc|cc}
\hline & \multicolumn{1}{c}{ Market Structure } \\
\cline { 2 - 9 } Pre-Merger & $B D$ & $B D$ & $B D$ & $B D$ & $B D$ & $B D$ & $B$ & $D C$ \\
Post-Merger & $B D$ & $B D C$ & $B C$ & $D C$ & $B$ & $D$ & $D$ & $B$ \\
\hline Consumer Welfare (\%) & -23.6 & 19.5 & -1.69 & -9.75 & -44.6 & -52.8 & -14.7 & -38.7 \\
Breyers' Var. Profits ( 4$)$ & 0.21 & -0.73 & 0.04 & -4.43 & 1.45 & -4.43 & -5.89 & 5.89 \\
Dreyers' Var. Profits (థ) & 0.11 & -0.65 & -3.46 & 0.21 & -3.46 & 1.53 & 4.99 & -3.67 \\
Composite firm's Var. Profits (థ) & & 2.81 & 3.30 & 3.47 & & & & -3.47 \\
\hline
\end{tabular}

Travel parameter fixed at 0.72, implying a diversion ratio from Breyers to Dreyers of $19 \%$. Values for the remaining demand and cost parameters in Table 2 Change in consumer welfare shown as percentage of pre-merger values. Changes in variable profits shown in cents per unit of market size.

merging firms' fixed costs are low, such that the decreased pricing pressure from the merger results in $C$ being offered and the merging parties retaining both products. Consumers benefit significantly in this scenario - see Table 3 - and the merging firms profits are hurt, as the situation is akin to Cabral (2003). For larger fixed cost values of $C$, the composite brand enters only if the merging firms cull a product, which they do whenever either Breyers' fixed cost or Dreyers' fixed costs are high. In these scenarios, consumers are almost unaffected by the merger whenever Dreyers' is the culled product, as the composite brand's product is similar to Dreyers. However, consumers are slightly hurt whenever Breyer's is culled, as it has higher innate demand than the composite brand's product. Finally, for large values of $C$, the composite brand never enters and consumers are left worse off from either increased prices, from Dreyer's being culled, and worst of all from Breyer's being culled. In any of these three cases, the merging firms benefit with from the merger, as the composite brand does not enter.

There are two key takeaways from this analysis. First, when considering which products may be culled as a result of a merger, it is not sufficient to consider the innate demand for the product. Costs, both fixed and variable, also affect a firm's choice to offer, or cull, a product. Hence, the merged firm will not necessarily cull the product with the lowest demand, as this product must necessarily have a low fixed cost given that the firms chose to offer it pre-merger. Second, the ability of a potential entrant to rapidly enter a market in response to the merged firm culling products significantly limits the consumer welfare loss from the merger, even when such a potential entrant is not particularly strong. The ability of rivals to readily enter is sufficient to limit consumer welfare losses from merger-induced product variety changes. 


\subsubsection{Equilibrium selection effects}

As we discuss in the introduction to Section 3.2 , the product offering and pricing model applied to the calibrated ice cream setting - or the earlier hypothetical symmetrical industry - does not yield unique equilibrium predictions for product portfolio choices across all combinations of fixed cost and travel parameter values. When multiple equilibria exist, the model itself does not make predictions for the product offering that would prevail in practice. As a result, it is possible that in the pre-merger equilibrium, firm decisions result in product portfolios that do not generate the highest aggregate profit or welfare. The set of possible equilibria is smaller post-merger, as the merging parties now jointly decide which of their products to offer, ruling out equilibria where the less profitable of their two products is offered when the market can sustain only one of their two products, but not both. In this section, we illustrate how this reduction in the equilibria set can result in consumer welfare loss and in the crowd-out of rivals.

In the previous section we mentioned how the merging firm would choose to cull the highdemand product, Breyers', whenever costs of this product were sufficiently high vis-a-vis those of Dreyers. Not surprisingly, the same logic holds when analyzing a pre-merger market structure in which only Breyers is offered. In particular, panel (a) in Figure 7 shows the postmerger post-merger market outcomes for different values of Breyers' and Dreyers' fixed costs, conditioning on fixed costs that are consistent with a pre-merger market structure of $B .{ }^{12}$ There, one observes how there exist fixed cost values for which the merger induces a swap of a high demand product, Breyers, for a low-demand (and low cost) product, Dreyers. Such swap, although beneficial for the merging firms, is detrimental to consumers, i.e. consumer welfare drops by $15 \%$, as shown in Table 3 .

The above scenario was feasible because, pre-merger, there were multiple equilibria, i.e. offering only Breyers or only Dreyers were both equilibria. Another setting in which the merger results in a reduction in equilibria, and therefore a switch from one equilibrium to another, occurs when the pre-merger market structure is $D C$ : Dreyers and the composite firm each offer a product, and Breyers does not. For such pre-merger market structure, there are feasible fixed cost values for which Breyers' alone would also be an equilibrium, but one from which firms coordinated away. For a subset of these fixed cost values, the merging parties are best off swaping Dreyers' product with Breyers', and to which the composite firm responds by not offering their product. Panel (b) in Figure 7 illustrates this case, and Table 3 displays the corresponding effects on consumer welfare and products' variable profits.

12 As with the previos section, we fix the travel parameter at 0.72 , which implies a diversion ratio from Breyers to Dreyers of $19 \%$. The results are qualitatively similar for alternative parameter values, with the only change that fixed cost values determining each post-merger market structure shift. 
Briefly, such equilibrium switch, from $D C$ to $B$, results in a $38 \%$ loss in consumer welfare, due to the reduction in competition and reduction in variety, reductions which are not offset by the presence of a higher quality product (i.e. Breyers).

Figure 7: Market outcomes conditional on alternative pre-merger market structures

(a) Pre-merger market structure of $B$

Asymmetric fixed costs - composite brand never offered

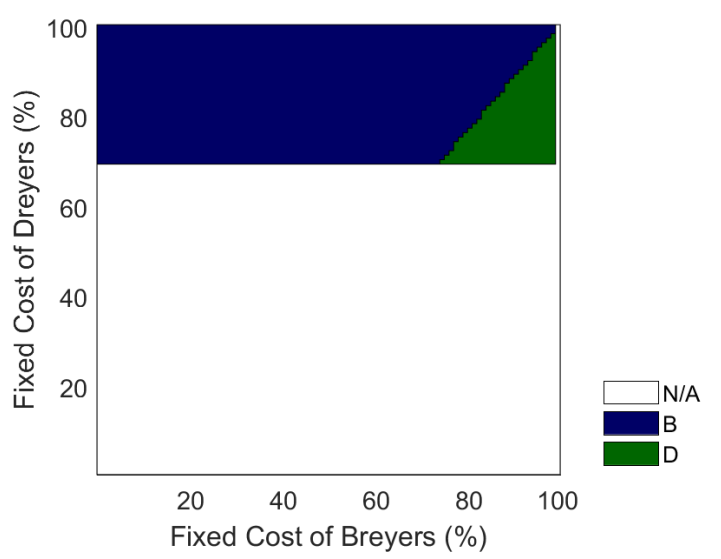

(b) Pre-merger market structure of $D C$ Asymmetric fixed costs

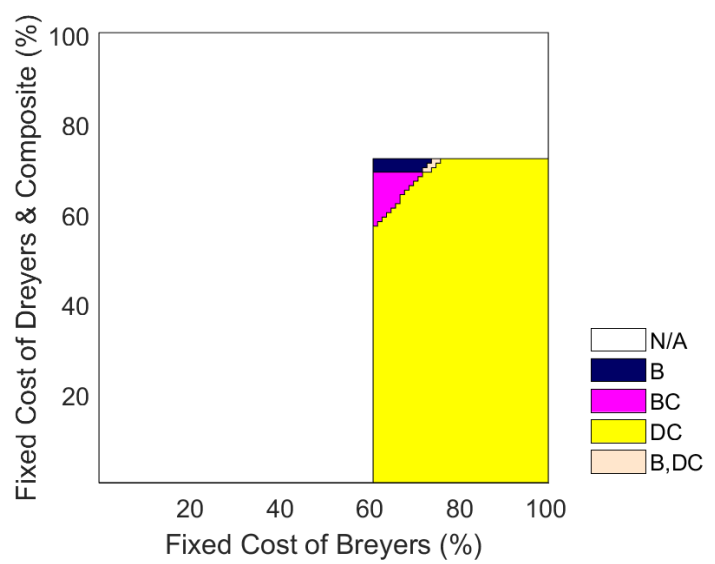

Fixed costs shown as a percentage of each brand's monopolist variable profits. We set $\rho$ at 0.72 , which implies a diversion ratio from $B$ to $D$ of $19 \%$. See caption in Figure 5 for detail.

In its unsuccessful attempt at blocking the 2003 Oracle-PeopleSoft merger in court, the Department of Justice argued that rivals would not adjust their offerings after the merger, thereby leaving anti-competitive price increases by the merging parties unconstrained. ${ }^{13}$ This example suggests that merging parties may be able to exclude the non-merging firm from the market even without decreasing pricing pressure. That said, post-merger portfolio coordination could also have the opposite effects, where the products offered post-merger have higher innate demand, therefore positively affecting consumers, or lower competitive pressure, therefore inducing entry by rivals.

In summary, the analysis of the product variety effects of a merger in the more realistic, empirically motivated, icecream setting reinforces many of the conclusions from the setting with symmetrically differentiated products. Our results highlight several sources of consumer welfare effects of product variety adjustment that do not arise in the symmetric case, however. Such effects reflects the relationship between the innate demand for a variety and thus its variable profit potential relative to the cost of offering the product. We find that the potential for consumer welfare losses from a merger is highest when both innate demand and fixed costs are high, making such products unattractive to offer despite high willingness-to-pay. The

13 See McAfee et al. (2007) for a detailed overview of the alleged anti-competitive effects of this particular merger. 
potential for post-merger variety adjustments thus crucially depends on product placement in characteristic space, which we take as exogenously given. An interesting extension of our analysis would allow not only the size of, but also the characteristics of products in, the merged firm's portfolio to change with a merger. Firms adjusting the characteristics of their remaining products to more closely target concentrations in demand may offset some of the consumer welfare effects of merger-induced product culling when product offering costs are significant.

\section{Cost Efficiencies}

In the above simulations, we have focused on the strategic incentives to re-optimize product offerings when only product ownership, but no other economic primitives of the industry, change. A common motivation for mergers is, however, the potential to generate cost efficiencies for merging parties. A natural question is therefore how large any such cost efficiencies have to be to leave consumers weakly better off after the merger or to offset any strategic incentives to change the number of products offered post-merger. Farrell and Shapiro (1990) take a first pass at this question in a symmetric Cournot setting, calculating the size of the variable cost efficiencies that are sufficient to counter the reduction in pricing pressure postmerger. ${ }^{14}$ In our setting, such efficiencies may similarly take the form of reductions in the marginal cost of producing and distributing a product or arise due to increased economies of scope associated with offering products. The latter could potentially lead to less frequent culling, when pre-merger all products are in the market, thereby limiting any negative welfare implications of a merger to those induced by price effects. Similarly, cost synergies might increase variety in when, pre-merger, firms offer only a subset of available products, as in Sections 3.1 .2 and 3.1.3. The resulting increase in variety may offset some, or all, of the negative welfare implications of the merger. We begin by considering such fixed cost efficiency gains from a merger, before turning to variable cost efficiencies.

\subsection{Fixed Cost}

To investigate the possibility of fixed cost synergies reducing merger-related product culling incentives, we simulate market outcomes when economies of scope accompany the merger. Given the demonstrated significant culling incentives, we consider our base setup with three symmetrically horizontally differentiated products with identical fixed costs. As in Section 3.1.1, we condition on combinations of fixed cost and travel parameter values that entail all

14 Other work on this question includes Levin (1990) and McAfee and Williams (1992). 
Figure 8: Minimum merger-induced cost efficiencies to preserve a pre-merger market structure of $A B C$

(a) Fixed Cost Savings

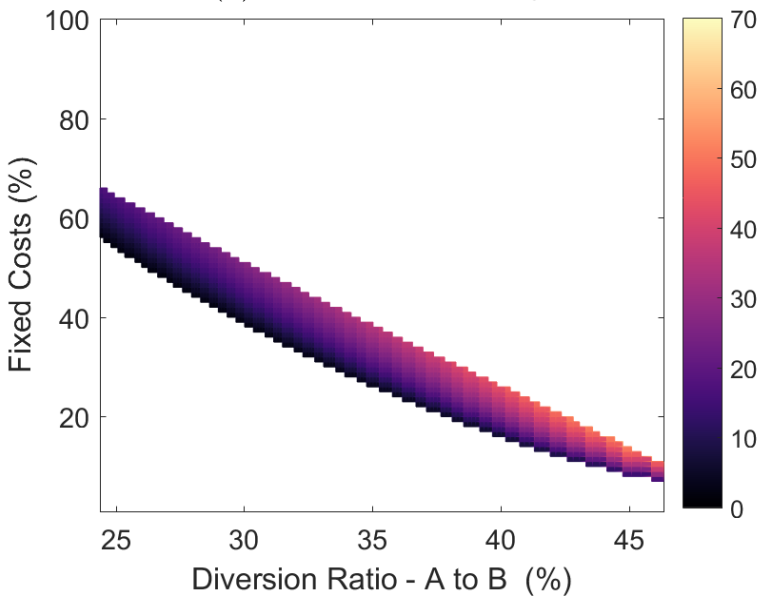

(b) Variable Cost Savings

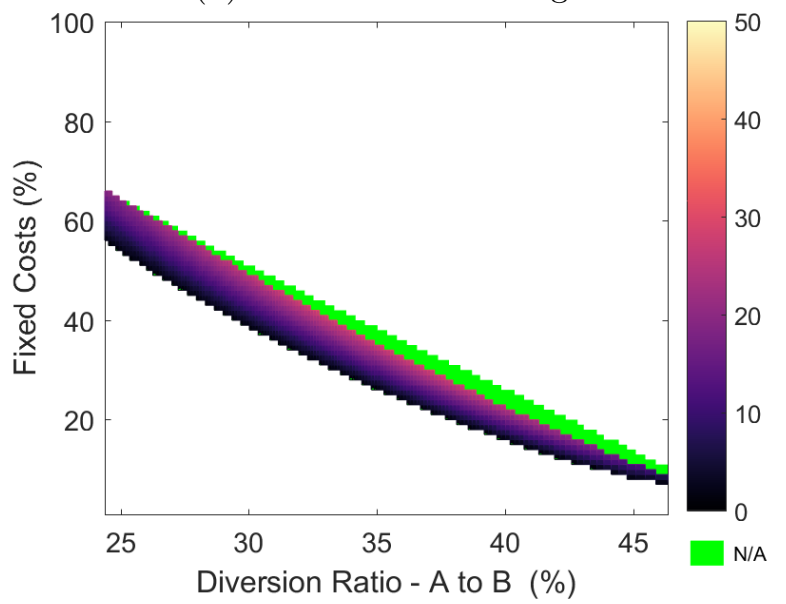

Graphs show outcomes for fixed cost and travel parameter values that give rise to a pre-merger market structure of $A B C$ but a different post-merger market structure absent any cost efficiencies. Demand and cost parameters as given in Table 1 We shade in black parameter combinations for which no level of cost efficiency can preserve the pre-merger market structure of $A B C$. We label these "N/A". See caption in Figure 1 for detail.

three firms offering their product pre-merger. Furthermore, we consider only fixed cost and travel parameters that post-merger result in culling, with the market structure no longer being $A B C$. In the absence of cost efficiencies, the merger thus entails reductions in product variety for consumers. We then ask by how much the merged firm's fixed product offering costs would need to decrease at a minimum for them to continue to choose to offer both products post-merger. As firms are endowed with a single product each, such fixed-cost efficiencies amount to economies of scope that are achieved solely through merger activity. We operationalize these fixed cost efficiencies by reducing the fixed costs of both products $A$ and $B$ by a fixed percentage. Post-merger, product $C$ thus has higher product offering costs than the merged firm. ${ }^{15}$

We display the resulting cost efficiencies in Figure 8. Panel (a) shows, for each level of the three products' fixed cost, $g$, and travel parameter, $\rho$, the minimum percentage of fixed cost savings for products $A$ and $B$ to preserve the $A B C$ market structure post-merger when a product would be culled otherwise. That is, we shade values of the cost efficiency percentage $e_{1}$ such that post-merger, $g_{A}^{\text {post }}=g_{B}^{\text {post }}=\left(1-e_{1}\right) \times g_{i}$ and $g_{C}^{\text {post }}=g_{i}$ for each relevant fixed cost realization $g_{i}$. The size of the required synergies range from 0 to $100 \%$ of fixed cost. When a merging party is on the margin between culling a product or continuing to offer it

15 The extent of such synergies is of course specific to the circumstances of the merging parties. A figure of 15-20 percent cost savings was cited in the 2001 proposed, but ultimately blocked, merger between baby food manufacturers Beech Nut and Heinz, for example. See Baker (2004). 
because fixed costs pre-merger are relatively low (the lower boundary of the shaded region in panel (a)), minimal cost savings are sufficient to preserve the existing market structure. In contrast, the largest cost synergies required occur near the top boundary, where pre-merger, the offered products generate negligible profits and firms are indifferent between offering them or not. In such cases, for an intermediate diversion ratio of, say $35 \%$, the required cost synergies are $37 \%$. In all of these instances, price competition between the three products is weaker post-merger as the two merging parties internalize business stealing effects. This benefits product $C$, which continues to be offered regardless the level of fixed cost efficiencies. These results thus highlight that it is when a firm acquires a distressed asset that fixed cost synergies are essential to preserving market structure; very profitable assets are not likely to be culled.

\subsection{Marginal Cost}

The previous economies of scope in fixed costs eliminate the welfare effects associated with culling, but the merger still hurts consumers due to standard price effects. Economies of scope may affect not only fixed costs, but also variable costs. Variable cost savings have the potential to reduce culling incentives, while also limiting the firms' incentives to raise price above pre-merger levels. Here, we therefore explore how outcomes change when the merger results in symmetric marginal cost savings, but no fixed cost savings, for the merged firm's two products. We consider two scenarios. First, as above, we calculate the minimum variable cost savings required to preserve the pre-merger market structure of $A B C$. The effect of such merger-induced variable cost efficiencies on consumer welfare is ambiguous: the merged firm's joint pricing puts upward pressure on prices, but their lower variable costs puts downward pressure on prices. Hence we consider a second scenario in which we calculate the minimum variable cost savings required to keep consumer welfare constant, irrespective of the resulting post-merger market structure. This second scenario mirrors the original analyses in Farrell and Shapiro (1990)

We depict the minimum variable cost efficiencies in panel (b) of Figure 8. Here, we shade values of the cost efficiency percentage $e_{2}$ such that post-merger, $c_{A}^{\text {post }}=c_{B}^{\text {post }}=\left(1-e_{2}\right) \times c$ and $c_{C}^{\text {post }}=c$ for each relevant combinations of the fixed cost and travel parameters. The minimum variable cost savings required to preserve the $A B C$ market structure range from 0 to $30 \%$. As with the fixed cost savings, when post-merger the merging parties are near indifferent between culling a product or not, minimal variable cost savings are sufficient to preserve the pre-merger market structure. For low levels of differentiation, e.g., diversion ratios below $30 \%$, variable cost savings of $25 \%$ may be sufficient to preserve market structure, 
similar in magnitude to the required fixed cost savings that we depict in panel (a) of Figure 8. However, for higher diversion ratios or high fixed costs, the merging parties have a strong incentive to cull a product -the top boundary in the graph-, and there may be no variable cost synergies that can preserve the current market structure: variable cost savings need to be sufficiently high for the merged firm not to cull one of their products, but they cannot be so high as to to drive the non-merging firm out of the market, as it can no longer compete against the strengthened merged products. The closer products are to each other, on the right side of the graph, the larger the effect of a given level of variable cost savings is on the nonmerging product's profits. Hence it is when products are very close substitutes that it may not be possible to preserve the pre-merger market structure through variable cost synergies: either the merged firm or its non-merging rival will cull a product. These simulations point to more nuanced effects of cost synergies in the context of merger analysis than would arise in analysis that hold the firms' product offerings fixed post merger, as the improved strategic position that results from variable cost synergies may affect rival profitability so sufficiently that they exit, resulting in unintended consumer welfare reductions.

Figure 9: Minimum merger-induced variable cost efficiencies to preserve consumer welfare

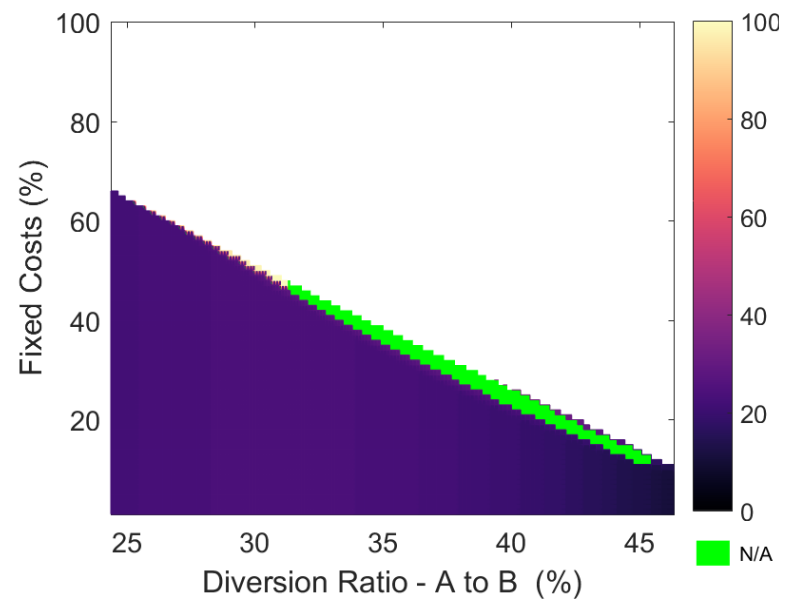

Graphs show outcomes for fixed cost and travel parameter values that give rise to a pre-merger market structure of $A B C$ absent any cost efficiencies. Demand and cost parameters as given in Table 1 We shade in black parameter combinations for whom no level of variable cost efficiency can generate a post-merger consumer surplus of at least the pre-merger value. These are labeled "N/A". See caption in Figure 1 for detail.

We depict the results of the second analysis, which calculates the minimum variable cost savings required to preserve consumer welfare, in Figure 9. For most travel parameters, variable cost savings of $15-25 \%$ are required to offset the price increases from decreased pricing pressure. However, for high fixed costs, there is again a region where variable cost savings alone are insufficient to preserve consumer welfare. This occurs as above because the merging parties have a strong incentive to cull a product, and refrain from doing so only with large variable cost savings that are so high that the non-merging firm exits the market and 
consumers are hurt. When products have high fixed product offering costs and are relatively close substitutes, there may thus be no efficiencies, in reducing either variable or fixed costs alone, that can preserve consumer welfare; efficienies would need to reduce both fixed and variable costs simultaneously to leave both product variety and prices unaffected.

\section{Conclusions}

In this paper, we have begun to analyze the potential welfare impacts of post-merger product choice decisions. While the courts and regulatory agencies have considered the potential for new offering decisions qualitatively, merger simulations have almost entirely focused on price effects. We demonstrate that post-merger product choice can have a substantial impact on industry equilibrium, significantly altering the impact on consumer welfare depending on the circumstances. Overall, the impacts are particularly acute in cases where the merged firm offered relatively similar products prior to the merger exacerbating the profit gains and consumer welfare losses the merger would otherwise produce. A simulation that allows for re-optimizing offering decisions can also accommodate the impact of fixed cost synergies, which tend to be positive for consumer welfare because the merged firm offers its products more often when fixed costs are lower. Similar to Gandhi et al. (2008), we impose initial pre-merger conditions on the degree of substitutability between products and firms' fixed product offering costs that are conducive to isolating the effect of individual mechanisms behind product offering adjustments with a merger, including product introductions due to higher prices, product removals or culling to save on fixed costs, and product adjustments arising from the merged firm's ability to coordinate on more profitable equilibria across a full set of products. We note that considering the full impact of product portfolio re-optimization is necessary to accurately simulate the merger's expected effect.

Our analysis considers two stylized demand scenarios. However, the modeling strategy employed here could also be adapted to compute post-merger product choice impacts in an actual merger simulation with more general demand models. As mentioned in Section 1, a number of researchers have been developing empirical techniques to accommodate product choice into merger analysis. Our approach is most applicable to a shorter-run analysis in which the industry's firms can optimize which existing product varieties to continue offering after a merger. Incorporating these effects, along with pricing impacts, increases the informative value of a merger simulation to regulatory agencies trying to judge the impact of mergers on consumers. An interesting avenue for future research would be an investigation of the longer-run effects of a merger on product positioning: how does the merged firm choose to adjust the characteristics of the products in its menu, in re-optimizing its product 
portfolio in the more concentrated environment?

In addition, while we have altered substitution patterns around values produced by our estimation exercise, the analysis is specific to the underlying features of this example. In particular, our calibrated demand is such that we have one relatively dominant firm (Breyers), an intermediate firm (Dreyers) and one weaker firm (Composite). The simulation results would be different depending on the context of the exercise; indeed, insights from any relevant combination or industry structure (including one representing conditions in a real merger scenario) could be generated using our framework once the demand estimates were determined and the available product menus were known. This could be a very useful guide for policy makers.

Finally, the analysis in the paper holds constant variable costs and most demand parameters, and analyzes merger effects across all feasible fixed costs values that give rise to a given pre-merger market strucutres. Alternatively, one could have held constant fixed costs, and analyse merger effects across feasible demand and variable cost values that justify the various pre-merger market structures. Although we expect the effects of such analysis to be qualitatively similar -i.e. reductions in product porftolios, increases in prices, swapping of low-profit products for higher-profit products, etc.-, they ought to be qualitatively different and worthy of study. As such, we leave such analysis for future research.

\section{References}

Aksoy-Pierson, Margaret, Gad Allon, and Awi Federgruen, "Price Compeition Under Mixed Multinomial Logit Demand Functions," Management Science, August 2013, 59 (8), 1817-1835.

Baker, Jonathan, "Efficiencies and High Concentration: Heinz Proposes to Aquire BeechNut," The Antitrust Revolution: Economics, Competition, and Policy, 2004, 150.

Berger, Allen N., Asli Demirgüç-Kunt, Ross Levine, and Joseph G. Haubrich, "Bank Concentration and Competition: An Evolution in the Making," Journal of Money, Credit and Banking, 2004, 36 (3), 433-451.

Berry, Steven, Alon Eizenberg, and Joel Waldfogel, "Optimal product variety in radio markets," RAND Journal of Economics, 2016, 47 (3), 463-497.

_, James Levinsohn, and Ariel Pakes, "Automobile Prices in Market Equilibrium," Econometrica, July 1995, 63 (4), 841-890. 
Budzinski, Oliver and Isabel Ruhmer, "Merger Simulation in Competition Policy: A Survey," Journal of Competition, Law \& Economics, 2010, 6, 277-319.

Cabral, Louis, "Horizontal Mergers with Free Entry: Why Cost Efficiencies may be a Weak Defense and Asset Sales a Poor Remedy," International Journal of Industrial Organization, 2003, 21, 607-623.

Caplin, Andrew and Barry Nalebuff, "Aggregation and Imperfect Competition: On the Existance of Equilibrium," Econometrica, Jan 1991, 59 (1), 25-59.

Draganska, Michaela, Michael J. Mazzeo, and Katja Seim, "Beyond Plain Vanilla: Modeling Joint Product Assortment and Pricing Decisions," Quantitative Marketing and Economics, 2009, 7, 105-146.

Fan, Ying, "Ownership Consolidation and Product Characteristics: A study of the US Daily Newspaper Market," American Economic Review, 2013, 103, 1598-1628.

_ and Chenyu Yang, "Competition, Product Proliferation and Welfare: A Study of the US Smartphone Market," working paper, 2018.

Farrell, J. and C. Shapiro, "Horizontal Mergers: An equilibrium analysis," American Economic Review, 1990, 80, 107-126.

Gandhi, Amit and Jean-Francois Houde, "Measuring Substitution Patterns in Differentiated Products Industries," working paper, 2016.

_, Luke Froeb, Steven Tschantz, and Gregory J. Werden, "Post-Merger Product Repositioning," Journal of Industrial Economics, 2008, 56, 49-67.

Gowrisankaran, Gautam, "A Dynamic Model of Endogenous Horizontal Mergers," RAND Journal of Economics, 1999, 30, 56-83.

Hotelling, Harold, "Stability in Competition," Economic Journal, 1929, 39, 41-57.

Jeziorski, Prezmek, "Estimation of Cost Synergies from Mergers: Application to the US Radio," RAND Journal of Economics, 2014, 45 (4), 816-846.

Levin, D., "Horizontal Mergers: The 50-percent benchmark," American Economic Review, 1990, 80, 1238-1245.

Li, Sophia, Joe Mazur, Yongjoon Park, James Roberts, Andrew Sweeting, and Jun Zang, "Endogenous and Selective Service Choices after Airline Mergers," working paper, 2018. 
Marino, Anthony and Jan Zabojnik, "Merger, Ease of Entry and Entry Deterrence in a Dynamic Model," Journal of Industrial Economics, 2006, 54, 397-423.

McAfee, Preston, David Sibley, and Michael Williams, "Oracle's Acquisition of PeopleSoft: U.S. v. Oracle," in Lawrence White, David Sibley, and Michael Williams, eds., Antitrust Revolution, fifth edition ed. July 2007.

McAfee, R. P. and M. A. Williams, "Horizontal Mergers and Antitrust Policy," Journal of Industrial Economics, 1992, 40, 181-186.

McFadden, Daniel, "Conditional Logit Analysis of Qualitative Choice Behavior," in P. Zarembka, ed., Frontiers of Econometrics, Academic Press, 1973, pp. 105-142.

Murphy, Kevin, "FTC vs Whole Foods Market, Inc., Export Report," July 2007, Civ. No. 1:07-CV-01201.

Nevo, Aviv, "Mergers with Differentiated Products: The Case of the Ready-to-Eat Cereal Industry," RAND Journal of Economics, 2000, 31, 395-421.

Seim, Katja and Joel Waldfogel, "Public Monopoly and Economic Efficiency: Evidence from the Pennsylvania Liquor Control Board's Entry Decisions," American Economic Review, 2013, 103 (2), 831-862.

Spector, David, "Horizontal Mergers, Entry, and Efficiency Defenses," International Journal of Industrial Organization, 2003, 21, 1591-1600.

Vives, Xavier, Oligopoly Pricing: old ideas and new tools, 1st ed. ed., MIT Press, 2001.

Werden, Gregory J. and Luke Froeb, "The Entry-Inducing Effects of Horizontal Mergers," Journal of Industrial Economics, 1998, 46, 525-543.

Wollmann, Thomas, "Trucks without Bailouts: Equilibrium Product Characteristics for Commercial Vehicles," working paper, 2016. 


\section{Web Appendix}

\section{A Calibration of Model Parameters for Premium Ice Cream Example}

In this Appendix, we describe how we estimate a discrete choice demand model for vanilla flavored ice cream. The U.S. ice cream market has two leading national suppliers - Breyers and Dreyers - and various regional players that operate across markets. These firms offer a multitude of flavors each, even within subcategory; we focus on vanilla flavors of which firms offer up to six. We initially assume all regional brands make up a single composite brand, but offer the various vanilla flavors we observe in the data. This allows us to estimate mean preferences and variation around them - and thus our source of vertical differentiation between firms - for the two market leaders and a single fringe competitor, to match the setup in our simulations. We then use the estimated demand system to generate a parameterization of preference and cost distributions for a product set that is limited to one product per firm, while matching aggregate patterns of demand from the actual ice cream market in terms of preference heterogeneity and price sensitivity. The demand and marginal cost parameters we employ in the simulations are thus only approximations of the ice cream market due to aggregation; for example, the average price elasticity for the three products in our simulations would typically not equal the average price elasticity in a market with a much larger set of differentiated flavors.

Ice Cream Data We observe monthly sales (quantity and revenue) of ice-cream in 63 US geographic markets from July 2003 to June 2005. ${ }^{16}$ We focus on the premium vanilla ice cream category sold in 3.5 and 4 pint containers. Between the two nationwide manufacturers and the composite third brand, there are a total of 14 premium vanilla flavors in the data. We use the monthly sales of each flavor in each market, together with the assumption that the potential premium vanilla ice cream market is defined by the monthly per-capita consumption of all premium ice cream flavors (i.e. vanilla and non-vanilla flavors) estimated in the trade press, scaled by each market's population, to estimate market shares for the flavors and the outside good of non-vanilla premium ice cream consumption.

Estimating Demand for Premium Vanilla Ice Cream In estimating a randomcoefficients demand system, we allow the utility of each product (a brand-flavor pair) to

16 For an in-depth description, see Draganska et al. (2009) 
vary with price, brand, flavor, and demographic variables that capture overall demand for vanilla ice cream. We specify heterogeneous preferences for price, brand, and flavors as follows. The three ice cream brands offer a set of flavors each. There are a total of $J$ brandflavor combinations and $j$ indexes one of these. Consumer $i$ 's utility from purchasing one container of ice cream $j$ in market $n$ is given by

$$
\begin{aligned}
u_{i j n} & =\theta_{j n}+\tilde{\theta}_{i j n}+\epsilon_{i j n} \\
\theta_{j n} & =\alpha p_{j n}+x_{j n}^{(1)} \beta+\zeta_{j n} \\
\tilde{\theta}_{i j n} & =x_{n j}^{(2)} \Sigma_{\theta} \varepsilon_{n i}
\end{aligned}
$$

where $\epsilon_{i j n}$ is distributed according to a type one extreme value distribution with scale parameter equal to one, $\zeta_{j n}$ is a common unobserved product-market specific taste shock, $\varepsilon_{n i}$ is a $4 \times 1$ standard normal shock, $\Sigma_{\theta}$ is a symmetric $4 \times 4$ matrix, and $x_{j n}^{(1)}$ and $x_{j n}^{(2)}$ are vectors of product-market characteristics. $x_{j n}^{(1)}$ includes the market specific covariates of average temperature, percentage of African-Americans, percentage of males, percentage of individuals in the age groups of 18-24, 25-44, 45-64, and 65-and-above, average household size, median household income, number of WalMart stores, brand and flavor fixed effects, month fixed effects, and region fixed effects. See Draganska et al. (2009) for details on the importance of these covariates as demand shifters. $x_{j n}^{(2)}$ is comprised of price and brand dummies. $\Sigma_{\theta}$ has the form

$$
\Sigma_{\theta}=\left[\begin{array}{cccc}
\sigma_{p} & 0 & 0 & 0 \\
& \sigma_{B} & \rho_{B D} & \rho_{B C} \\
& & \sigma_{D} & \rho_{D C} \\
& & & \sigma_{C}
\end{array}\right]
$$

We thus assume that price responsiveness is distributed normal, with mean $\alpha$ and variance $\sigma_{P}$. Preferences over brands are assumed to be distributed joint-normal, with distinct mean values for each of the three brands $\left\{\beta_{B}, \beta_{D}, \beta_{O}\right\}$ and a completely flexible variance-covariance matrix that captures correlations in heterogeneous preferences across brands. We allow for flavor-specific departures from mean brand preferences through flavor dummies. The utility from not purchasing is given by $u_{i n 0}=\epsilon_{i n 0}$.

Integrating over the random shocks $\epsilon$ and $\varepsilon$, the predicted share of a given brand-flavor is

$$
s_{j}(x, \xi, \theta)=\int \frac{e^{\alpha p_{j n}+x_{j n}^{(1)} \beta+x_{j n}^{(2)} \Sigma_{\theta} \varepsilon_{n i}+\zeta_{j n}}}{1+\sum_{t \in J_{n}} e^{\alpha p_{t n}+x_{t n}^{(1)} \beta+x_{t n}^{(2)} \Sigma_{\theta} \varepsilon_{n i}+\zeta_{t n}}} d N(\varepsilon) \quad \forall j \in J_{n}
$$


Let $s_{n}^{\star}=\left(s_{1 n}^{\star}, \ldots, s_{J_{n} n}^{\star}\right)^{\prime}$ be the observed market shares. Berry et al. (1995) and Nevo (2000) show how using observed shares, one can invert the system of demand equations in Equation 15 by way of Monte Carlo integration to obtain the residual, $\zeta_{j n}$, as a linear function of the covariates

$$
\zeta_{n j}=s^{-1}\left(s_{n}^{\star}, x, \Sigma_{\theta}\right)-\alpha p_{j n}+x_{j n}^{(1)} \beta \quad \forall j \in J_{n} \forall n
$$

Given a 1-by- $K$ vector of instruments $\boldsymbol{z}_{j n}$, we then estimate the parameter vector $\theta=$ $\left(\alpha, \beta, \sigma_{p}, \sigma_{B}, \sigma_{D}, \sigma_{O}, \rho_{B D}, \rho_{B O}, \rho_{D O}\right)$ by minimizing the GMM objective function

$$
\begin{aligned}
Q_{N}(\theta) & =\boldsymbol{m}_{N} \Omega \boldsymbol{m}_{N}^{\prime} \\
\boldsymbol{m}_{N} & =\sum_{n=1}^{N} \sum_{j \in J_{n}} \boldsymbol{z}_{j n} \zeta_{j n} \\
\Omega & =\left(\sum_{n=1}^{N} \sum_{j \in J_{n}} \boldsymbol{z}_{j n}^{\prime} \boldsymbol{z}_{j n}\right)^{-1}
\end{aligned}
$$

where $n$ indexes the $N=1,449$ market-months (63 markets over 23 months) detailed above.

We follow Gandhi and Houde (2016) in choosing instruments. As prices do not vary across flavors of the same brand and there is limited temporal variation in brand pricing within a market, we do not instrument for price. Thus, the remaining parameters that we seek to identify with exclusion restrictions are the parameters of the variance-covariance matrix of the brand-level tastes. We include (a) the variance in price differences a product has with all other products in the same market: $z_{j n}^{\sigma_{p}}=\frac{1}{J_{n}-1} \sum_{t \in J_{n} \backslash j}\left(p_{j n}-p_{t n}\right)^{2}$; (b) for each brand, the number of flavors offered by the brand in a given market: e.g. $z_{j n}^{\sigma_{B}}=$ $J_{n B} \cdot 1\left\{j \in J_{n B}\right\}+\left(J_{n}-J_{n B}\right) \cdot 1\left\{j \notin J_{n B}\right\}$, where $J_{n B}$ is the number of Breyers' flavors offered in market $n$ and $1\{\cdot\}$ is the indicator function; (c) for each pair of brands, the total number of unique vanilla flavors offered by the two brands together: e.g. $z_{j n}^{\rho_{B D}}=\left(J_{n B}+J_{n D}\right)$. $1\left\{j \in J_{n B} \cup J_{n D}\right\}+\left(J_{n}-J_{n B}-J_{n D}\right) \cdot 1\left\{j \notin J_{n B} \cup J_{n D}\right\}$. Each of these instruments proxy for the availability of close products to the product under consideration, in terms of products offered by the same brand or of the same type, or of similar prices (limited variation in price differences to other products). Comparing the market shares for the product, and the brand's aggregate market share relative to that of flavors produced by other brands, in situations where the brand offers many flavors versus in situations where it offers few, allows identification of the degree of brand-specific heterogeneity in preferences from observing how much substitution occurs to similar versus less similar products. In using variation in price differences, we implicitly exploit our assumption above that price at the level of the flavor is not endogenously determined. 
We calculate brand-level elasticities as

$$
\begin{aligned}
\xi_{b b^{\prime} n} & =\frac{p_{b^{\prime} n}}{\hat{s}_{b n}} \frac{d \hat{s}_{b n}}{d p_{b n}} \quad \forall\left(b, b^{\prime}\right) \in\{B, D, O\}^{2} \\
\hat{s}_{b n} & =\sum_{j \in J_{n B}} s_{j}(x, \hat{\zeta}, \hat{\theta})
\end{aligned}
$$

where $\hat{\theta}$ and $\hat{\zeta}$ are the estimated parameters and residuals. The parameters and confidence intervals are available from the authors upon request.

\section{B A merger with commitment}

The analysis with symmetric fixed costs highlights that the merged firm's incentive to cull a product results in the rival product entering the market, leading to a loss of profit for the merged firm. One may worry that this result is an artifact of considering a static, simultaneous-move game; a richer dynamic model might not have such a prediction. Short of developing such a dynamic game of product positioning and pricing, we consider a static, sequential move game to explore the incentives the merging parties may have to retain a product to prevent rival entry. As in Section 3.1.2, we consider realizations of the fixed cost and travel parameters that result in a pre-merger market structure of $A B$ when firms choose product offering choices simulteanously. We change the post-merger game, however, so that firms move sequentially, instead of simultaneously, allowing the merging parties to make a choice of which products to offer first. Then, after observing the merged firm's product offering, firm $C$ decides whether to offer its product. Lastly, firms set prices given these offering decisions.

We depict the post-merger market structure resulting from this game in Figure 10. When firms move simultaneously, the post-merger market structure is $B C$ for all parameter values in the relevant subset (see panel (a) in Figure 3). Once the merged firm has the opportunity to commit to its offering choice prior to its rival, it indeed chooses to retain both products in the market when fixed costs are high. When fixed costs are low, however, this is not the most profitable strategy. Then, product $C$ enters even if the merged firm were to offer both products. Both the low fixed cost and the decreased pricing pressure exerted by the merged firm raise product $C$ 's profit sufficiently to merit entry even if it faced two competing products. Given that the merging parties can anticipate their rival's entry, it is optimal for them to offer one product only. This reduction in offered products limits the merging firms' profit loss from C's entry, but does not overturn it: the merging parties loose profits from this merger. As products are identical from the consumer's perspective, consumer welfare is 
Figure 10: Sequential-move game market outcomes conditional on a pre-merger market structure of $A B$

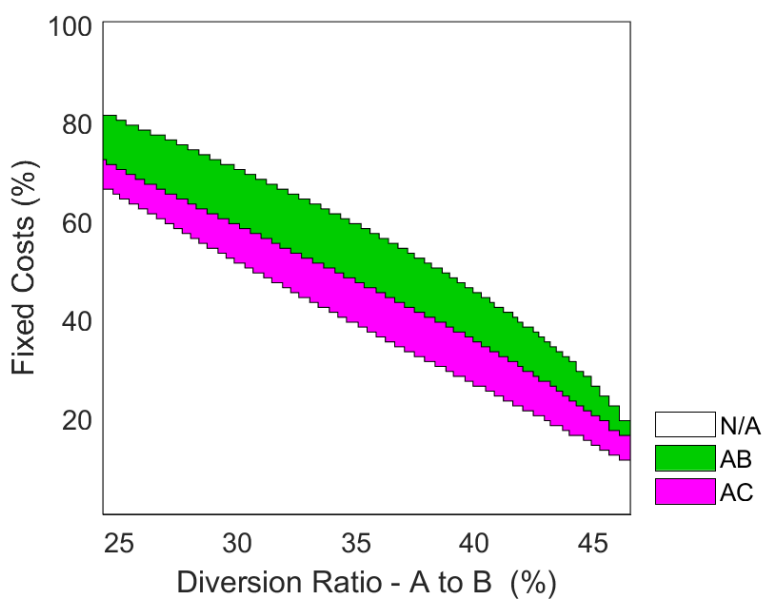

Graphs shows product offering decisions resulting from a sequential move game where the merging parties choose their product offerings first. Fixed cost and travel parameter values are those that give rise to a pre-merger market structure of $A B$ in the simultaneous move game. See caption in Figure 1 for detail.

unaffected when the post-merger market structure is $B C$. It decreases, however, when postmerger market structure is $A B$ because of the higher prices achieved through joint-pricing.

In summary, even when the merging incumbents are able to anticipate entry, their incentive to retain both products is limited when a low-cost potential entrant is in place to come in under the more concentrated market structure. 